\title{
Financial Constraints, Sectoral Heterogeneity, and the Cyclicality of Investment
}

\author{
Cooper Howes*
}

February 10, 2019

\begin{abstract}
While investment in most sectors declines in response to a contractionary monetary policy shock, investment in the manufacturing sector increases. Using manually digitized aggregate income and balance sheet data for the universe of US manufacturing firms, I show this increase is driven by the types of firms which are least likely to be financially constrained. A two-sector New Keynesian model with financial frictions can match these facts; unconstrained firms are able to take advantage of the decline in the user cost of capital caused by the monetary contraction while constrained firms are forced to cut back. Counterfactual exercises suggest that aggregate investment should become more strongly countercyclical as fewer sectors face financial constraints.
\end{abstract}

JEL Classification: E22, E32, E43, E44, E52

Keywords: Monetary policy, Investment, Financial frictions

*University of Texas at Austin, cooperhowes@utexas.edu. I would like to thank Saroj Bhattarai and Olivier Coibion for their guidance and support as well as Gabriel Chodorow-Reich, James Cloyne, Marco Del Negro, Aaron Flaaen, Marc Giannoni, Simon Gilchrist, Kevin Kuruc, Oleg Itskhoki, Victoria Ivashina, Dirk Krueger, Ali Ozdagli, Felipe Schwartzman, Alan Taylor, Choongryul Yang, and seminar participants at the University of Texas at Austin and Federal Reserve Bank of Boston for useful discussions and comments. I would also like to thank Dodge Analytics for generously providing building permit data. 


\section{Introduction}

Productive capital goods are among the most volatile and interest-sensitive components of GDP and receive significant attention from monetary policymakers. While past work such as Bernanke et al. (1999) and Christiano et al. (2005) has confirmed the conventional wisdom that aggregate investment is strongly procyclical in response to monetary shocks, these findings belie meaningful heterogeneity across sectors; in particular, investment in the manufacturing sector is strongly countercyclical conditional on monetary policy shocks. A model with financial constraints that vary across sectors can explain this behavior and suggests that the easing of financial constraints should lead to more strongly countercyclical aggregate investment dynamics.

I begin by establishing several new stylized facts regarding manufacturing investment using both aggregate and firm-level data. For my main analysis I use manually digitized aggregate data from the Quarterly Financial Report for Manufacturing Corporations (QFR), which contain detailed income and balance sheet information for the entire manufacturing sector dating back to 1966. I find the aggregate capital stock in the manufacturing sector increases by almost $2 \%$ in the years following a 100 basis point contractionary monetary shock. ${ }^{1}$ This increase is driven by the types of firms least likely to be financially constrained: large firms and those in the nondurables sector. There are two important properties of capital goods that can explain why firms would want to increase their investment expenditure in the face of falling demand.

The first is that the capital stock is long lived. This implies that investment decisions should be very forward looking; in the absence of frictions, transitory declines in consumer demand should have little impact on a firm's demand for long-lived capital goods since most of their benefit will come in the form of future service flows. The second is that the user cost of capital, which is the implied rental rate on the capital stock a firm owns, is strongly procyclical. Measures of user cost that use manufacturing-specific interest and depreciation rates from the QFR decline in response to contractionary monetary shocks across a variety of specifications. NIPA data suggest that structures, which have longer lives and more procyclical costs than other types of capital goods, are particularly important for explaining this investment behavior.

I analyze this mechanism in detail using data on building permits for new manufacturing structures from Dodge Analytics. While the number of new permits falls in response to contractionary monetary shocks, the total value of new permits rises. This suggests that, at least for structures, the increase in the value of the capital stock in manufacturing is driven by fewer, larger projects. To the extent that larger or more financially flexible firms are more likely to undertake

\footnotetext{
${ }^{1}$ I discuss existing work using the QFR data as well as the empirical techniques I use in Section 2.
} 
these kinds of projects, this is consistent with the idea that financial constraints are important for explaining capital stock dynamics. Analyzing the QFR financial data support this notion.

Small firms and those in the durable sector, neither of which increase their investment in response to a contractionary shock, exhibit a greater degree of financial constraint across several metrics commonly cited in the finance literature. They pay higher interest rates despite using less long-term debt, their cash flow is more volatile, and they have consistently lower dividend payout ratios. These features hold even when comparing only large firms within each sector, suggesting they are not driven solely by different firm size compositions across industries. In Section 3 I use quarterly firm-level data from Compustat and find the average manufacturing firm increases its investment in response to a contractionary monetary shock across all sectors. This is consistent with the idea that firms in Compustat are, simply by virtue of being publicly traded, less likely to be financially constrained than small, private, and bank-dependent firms. To analyze the quantitative importance of financial factors in explaining this investment heterogeneity across sectors, I incorporate them into a model.

An otherwise-standard New Keynesian model with financial constraints that differ across sectors is able to generate firm investment responses that are consistent with the data because it limits the ability of financially constrained agents to respond to changes in monetary policy. In the model, durable goods prices (which are flexible) fall in response to contractionary monetary shocks more than nondurable prices (which are sticky). This reduces the value of collateral held by the constrained durable producers, who are forced to reduce their durable purchases. Unconstrained nondurable producers are able to take advantage of the lower prices and increase their durable expenditure. Households, a fraction of which are also constrained, are affected by a similar mechanism that leads to declines in aggregate consumption in both the nondurable and durable sectors.

By generating on-impact investment and consumption responses consistent with the data, I am able to resolve the "comovement puzzle" first reported in Barsky et al. (2007), who pointed out that simple New Keynesian models predict large increases in durable purchases in response to contractionary monetary shocks due to their extreme forward-looking nature. This has led to a subsequent literature adding features such as sticky wages or financial constraints to match the data. ${ }^{2}$ While these fixes all generate comovement between both types of consumption, they do not have consistent predictions for the behavior of capital. Existing models without financial constraints will not generate this comovement, and imposing constraints on only one of households or firms cannot match the aggregate data. The model predicts that easing financial constraints

\footnotetext{
${ }^{2}$ These mechanisms are described in detail in Section 5 .
} 
on durable producers leads to investment that is more strongly countercyclical in all sectors.

These results have two important implications. First, they suggest policymakers should pay particularly close attention to the balance sheets of financially constrained firms when trying to use monetary policy as a tool to stabilize business cycles, as binding financial constraints can actually prevent them from adjusting and instead lead to increased activity in other, lessconstrained sectors. Second, to the extent that financial modernization can reduce these financial constraints in other sectors, more firms should able to take advantage of temporary demand-driven drops in capital goods prices.

\section{Evidence of Manufacturing Investment Cyclicality}

This section shows evidence from aggregate data that manufacturing investment is countercyclical conditional on monetary shocks and that this behavior can be explained by financial constraints. First, I use manually digitized historical data from the Quarterly Financial Report for Manufacturing Corporations to show that the aggregate manufacturing sector capital stock increases in response to a contractionary monetary shock. These effects are strongest for structures, which have longer lives and more cyclically sensitive prices relative to other types of investment, and building permit data suggest they are driven by the intensive margin. Many different empirical estimates of the user cost of capital fall in response to contractionary monetary shocks, suggesting that firms have an opportunity to benefit from short-term fluctuations in the prices of these long-lived investment goods. Finally, I demonstrate that large firms as well as those in the nondurables sector increase their investment most and that these are the types of firms least likely to be impacted by financial constraints.

\subsection{Data}

The main source of data I use is the Quarterly Financial Report for Manufacturing Corporations (QFR), a comprehensive survey of income and balance sheet information for the US manufacturing sector. A detailed description of the data can be found in Appendix A. Because data prior to 1987Q4 are only available in physical publications or microfilm- I digitized them manually going back to 1966Q1 from physical publications- there have been relatively few papers which have used them. The most famous example is Gertler and Gilchrist (1994), who used the data to suggest that small firms are more sensitive to monetary policy changes than large firms. Some more recent examples include Crouzet (2015), Crouzet and Mehrotra (2018), and Kudlyak and 
Sánchez (2017).

The QFR data are well suited for answering this question. First and foremost, they are representative of the entire manufacturing sector, including small and non-public firms. This is important because a large body of empirical evidence, including recent work such as Hadlock and Pierce (2010), finds small and non-public firms are more likely to be financially constrained. The data offer detailed balance sheet information at the quarterly frequency, which makes them better suited to analyze the responses of short-term fluctuations in monetary policy than annual BEA or Census data. And unlike the US Financial Accounts data, which aggregate balance sheet information across nonfinancial corporate businesses of all sectors and sizes, the QFR data provide sector-specific measures of financial ratios as well as capital stocks. While the QFR data do not have any firm-level detail, I show in Section 3 that the results from using aggregated data on the largest firms in the QFR are in line with the estimates obtained using firm-level data from Compustat as well as findings from other work that uses the QFR microdata.

\subsection{Empirical Responses to Monetary Shocks}

To analyze the empirical responses of consumption and investment to monetary policy shocks, I use a local projection specification based on Jordà (2005) and shown in Equation 1. In this setup $y_{t+h}^{i}$ represents the $h$-period ahead forecast of the log of the outcome variable $y$ for sector/size classification $i$ at time $t, \epsilon_{t}$ represents the monetary policy shock at time $t$, and $\nu_{t, h}^{i}$ is an error term.

$$
y_{t+h}^{i}=c_{h}^{i}+q_{h}^{i}+\text { Trend }+\sum_{j} \beta_{j, h}^{i} X_{t-j}^{i}+\sum_{k} \Omega_{k, h}^{i} Z_{t-k}+\gamma_{h}^{i} \epsilon_{t}+\nu_{t, h}^{i}
$$

I focus on sales and capital stocks as the outcomes of interest. ${ }^{3}$ I use the series developed by Romer and Romer (2004) (R\&R) and extended by Coibion (2012) as my measure of monetary policy shocks $\epsilon_{t}$. I include size-and-sector-specific controls in $X^{i}$ (8 lags of the dependent variable $y_{t}^{i}$ and 4 lags of real sales growth) and aggregate controls in $Z$ (4 lags of real GDP growth, 4 lags of $\epsilon_{t}$, and 1 lag of the durable share of sales). I also include a linear time trend and quarterly fixed affects $q_{h}^{i}$ to deal with seasonality. In line with R\&R, I start my sample in 1970 and include shocks through 2004. I do not consider outcomes beyond 2008 to avoid concerns surrounding the zero lower bound on nominal interest rates and the financial crisis. Appendix B shows that the conclusions are robust to alternate start dates and shock identification strategies.

\footnotetext{
${ }^{3}$ I use capital stocks instead of investment because they are directly recorded in the QFR data.
} 
The coefficient $\gamma_{h}^{i}$ represents the percent change in the $h$-period ahead forecast in variable $y$ for sector $i$. I use Newey-West standard errors to account for the serial correlation in residuals that arises from successively lagging the dependent variable. In Figure 1, I show the responses of sales and the capital stock.
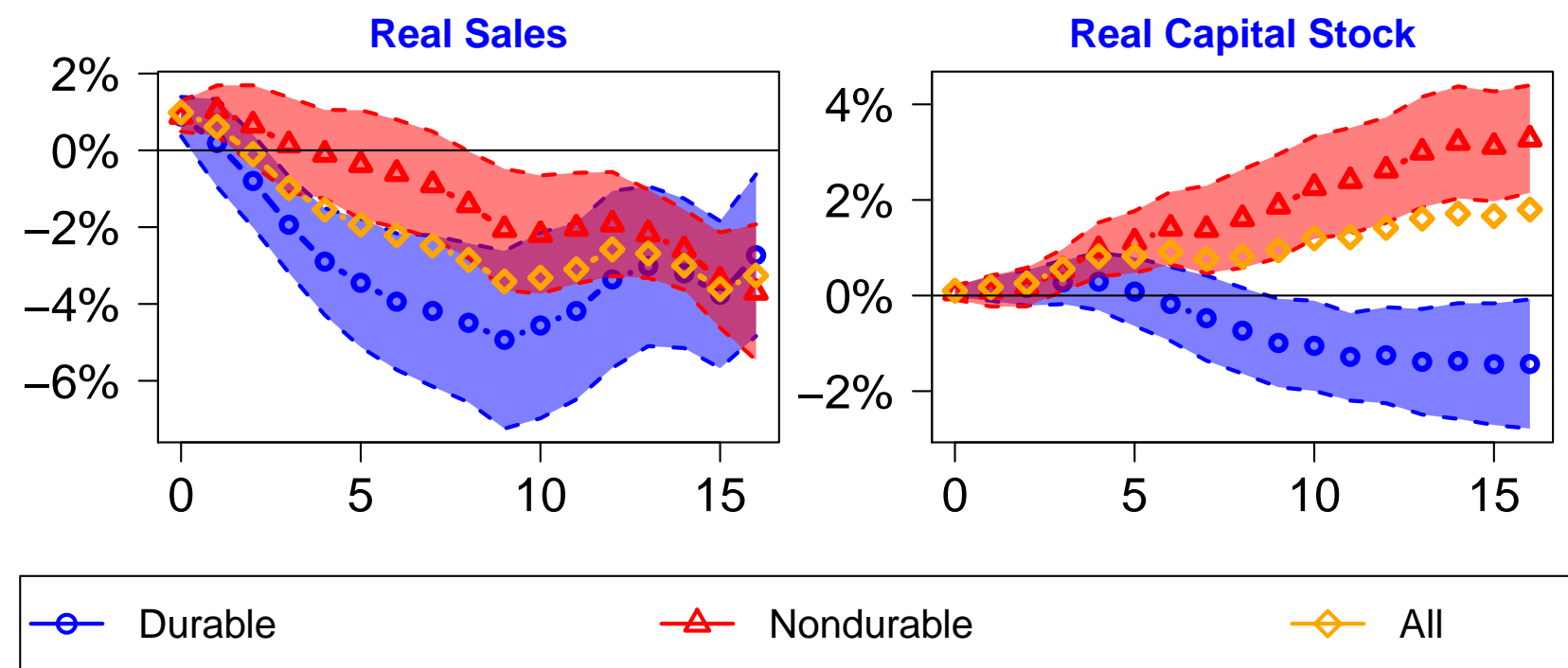

Figure 1: Empirical Responses to 100bp Contractionary MP Shock (90\% CI)

Note: This figure shows the coefficient estimates $\gamma_{h}^{i}$ from Equation 1, which correspond to the effects of a 100bp contractionary monetary shock. Sales are deflated using the BEA's manufacturing output deflator for each sector. NPPE is measured by the QFR item "Stock of Property, Plant, and Equipment Net of Depreciation" and deflated using the NIPA nonresidential fixed investment price index. 90\% confidence intervals are calculated using Newey-West standard errors. Regressions include shocks from 1970-2004 and outcomes through 2008.

Following a 100 basis point contractionary monetary shock, sales of manufacturing firms decline significantly, remaining 3-4\% below their pre-shock levels between three and four years after the shock. As in Erceg and Levin (2006), the drop is even larger for durable producers, who experience sales declines of up to $5 \%$. The capital stock of all manufacturers rises by about $1.8 \%$, and this is driven by a large and statistically significant increase of $3.2 \%$ on the part of nondurable producers. The capital stock of durable producers, on the other hand, declines by up to $1.4 \%$.

Figure 2 shows these results for firms based on asset size. The "big" firms include all firms with more than $\$ 1$ bn of nominal domestic assets, while the "small" firms include all others. In line with Gertler and Gilchrist (1994), I find that sales for small firms fall faster than for large firms in response to a monetary contraction, though this difference disappears after about two years; the left panel shows declines of about $4 \%$ for both by the end of the response horizon. The right panel shows that the increase in the capital stock is driven by large firms, who have highly significant coefficient estimates across virtually the entire response horizon and show a 
peak increase of just over $2 \%$, while the coefficients for small manufacturers are mostly close to zero and insignificant throughout the response horizon.

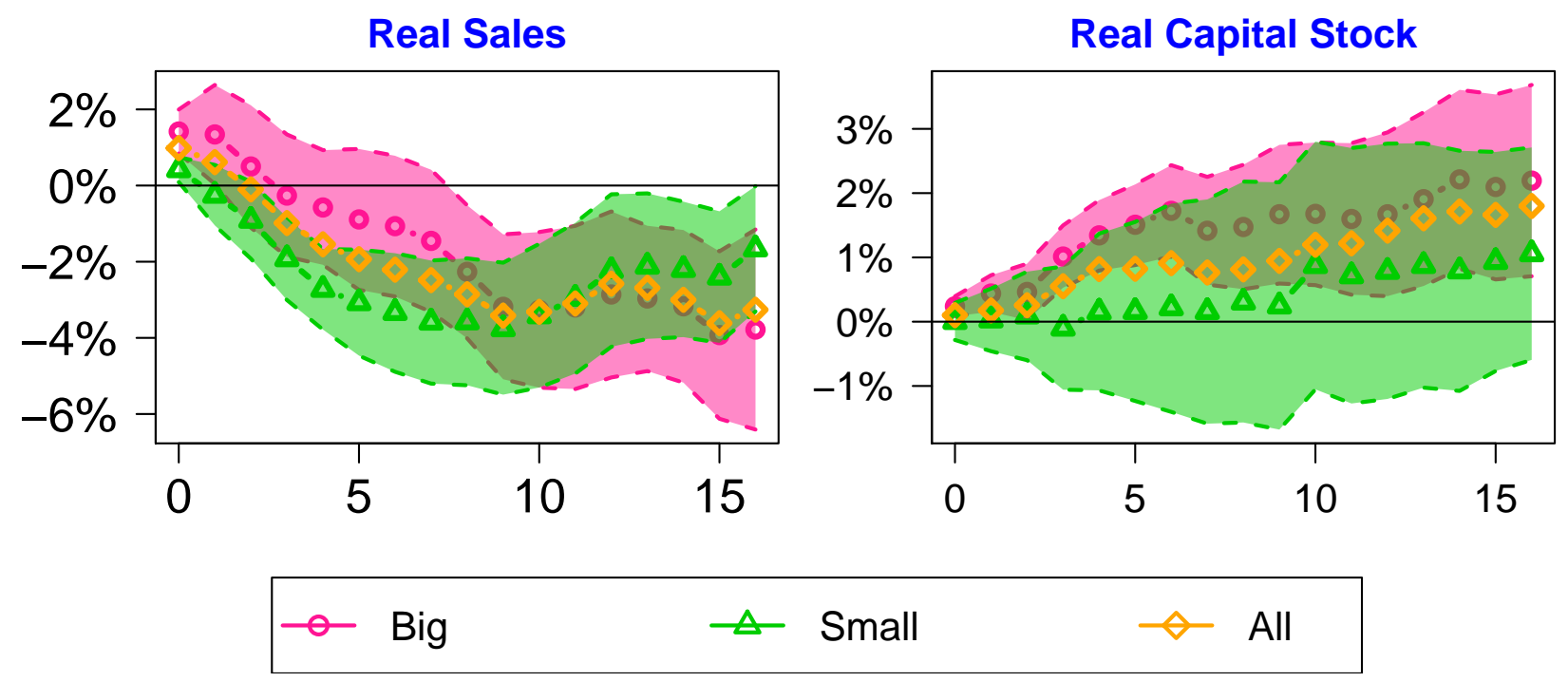

Figure 2: Empirical Responses to 100bp Contractionary MP Shock (90\% CI)

Note: This figure shows the coefficient estimates $\gamma_{h}^{i}$ from Equation 1, which correspond to the effects of a 100bp contractionary monetary shock. "Small" firms are defined as those with $<\$ 1$ bn in nominal assets and "Big" firms those with $\geq \$ 1$ bn in nominal assets. Sales are deflated using the BEA's manufacturing output deflator for each sector. NPPE is measured by the QFR item "Stock of Property, Plant, and Equipment Net of Depreciation" and deflated using the NIPA nonresidential fixed investment price index. 90\% confidence intervals are calculated using Newey-West standard errors.

Regressions include shocks from 1970-2004 and outcomes through 2008.

This countercyclical investment pattern in the manufacturing sector stands in contrast to most other sectors. While the historical QFR data do not have any information on industries outside of manufacturing, the BEA fixed asset accounts provide a useful alternative measure. These data provide estimates of the real capital stock for all sectors at an annual level. To analyze the effects of monetary policy, I create a quarterly series of fixed asset stocks for each industry by linearly interpolating the annual data. In principle the "Stock of Property, Plant, and Equipment" item in the QFR data should be a higher-frequency version of this measure, so it provides a useful check on the QFR results.

The left panel of Figure 3 shows the responses of the total fixed asset stock for a wide variety of sectors and shows several striking features. The first is that, as in the QFR data, the capital stock of the manufacturing sector increases in response to a contractionary monetary shock. The second is that the capital stocks of most other industries (including the aggregate) decline. The middle panel shows the response of equipment, which represents about $15 \%$ of the total capital stock for all industries. While the dispersion of responses is a bit higher than total fixed assets the pattern is quite similar. As in the total fixed asset case, manufacturing is clearly an outlier in 

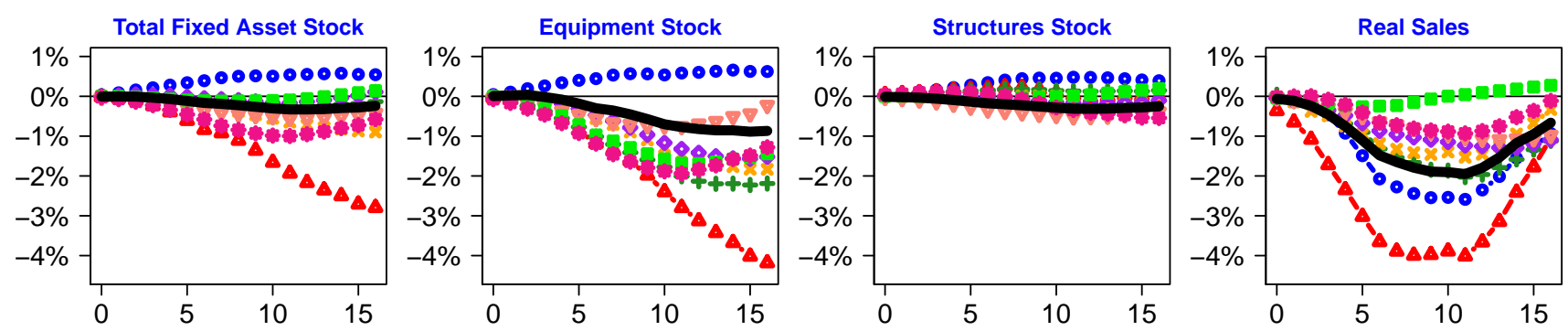

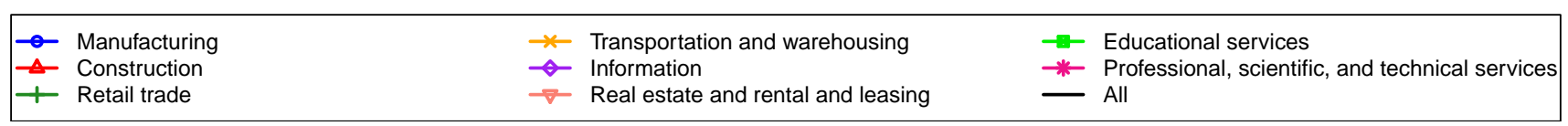

Figure 3: Empirical Responses to 100bp Contractionary MP Shock

Note: The first three panels use annual BEA on the real fixed asset stock for each sector. The fourth panel uses annual BEA data on the real output of each sector. A quarterly series is obtained from these annual series through linear interpolation. The estimating equation has the same structure and number of lags as Equation 1 but does not include lags of industry sales growth or the share of durable sales. Regressions include shocks from 1970-2004 and outcomes through 2008

terms of its countercyclical response. Structures, which represent around $80 \%$ of the total fixed asset stock of all firms in the economy, display more muted responses. And while the stock of structures in manufacturing has a more pronounced increase the stocks of several other industries (including construction and retail trade) climb as well. Finally, the rightmost panel shows that these increases in manufacturing investment occur despite a drop in sales that is larger than in most other industries. Overall, the BEA data suggest that the countercyclical behavior of the manufacturing sector capital stock is unique among sectors and that it occurs for both structures and equipment.

One possible reason for why the investment of manufacturing firms behaves differently from nonmanufacturing firms is outlined in Buera et al. (2011). The authors point out that manufacturing establishments generally operate at a larger scale than nonmanufacturing establishments and argue that these differences can be explained by higher fixed costs of operation, which must be financed. Thus while the manufacturing sector is more constrained ex ante, firms in this sector should on average be less financially constrained than their non-manufacturing counterparts conditional on operating.

\subsection{Structures Investment Detail}

Structures, which represent about $35 \%$ of the manufacturing capital stock based on BEA estimates, provide detailed evidence that the cost of new investment falls in response to contractionary monetary shocks and that financially unconstrained firms take advantage of these opportunities. 
The cost of new construction (including materials and wages) is strongly correlated with the residential housing market and thus falls sharply following a monetary contraction. These lower prices lead to large estimated increases in manufacturing construction. Detailed commercial building permit data show that this investment response is driven by the intensive margin: The number of new manufacturing structures falls while the total value of new structures rises. Assuming that larger firms build larger structures, this is consistent with the results shown for large firms in the previous section.

The most well-known measure of manufacturing structures investment data comes from the National Income and Product Accounts. As shown in Figure 4, there is a negative correlation (-0.33) between residential investment growth and manufacturing structures investment growth. The divergence between these series is particularly pronounced around recessions.

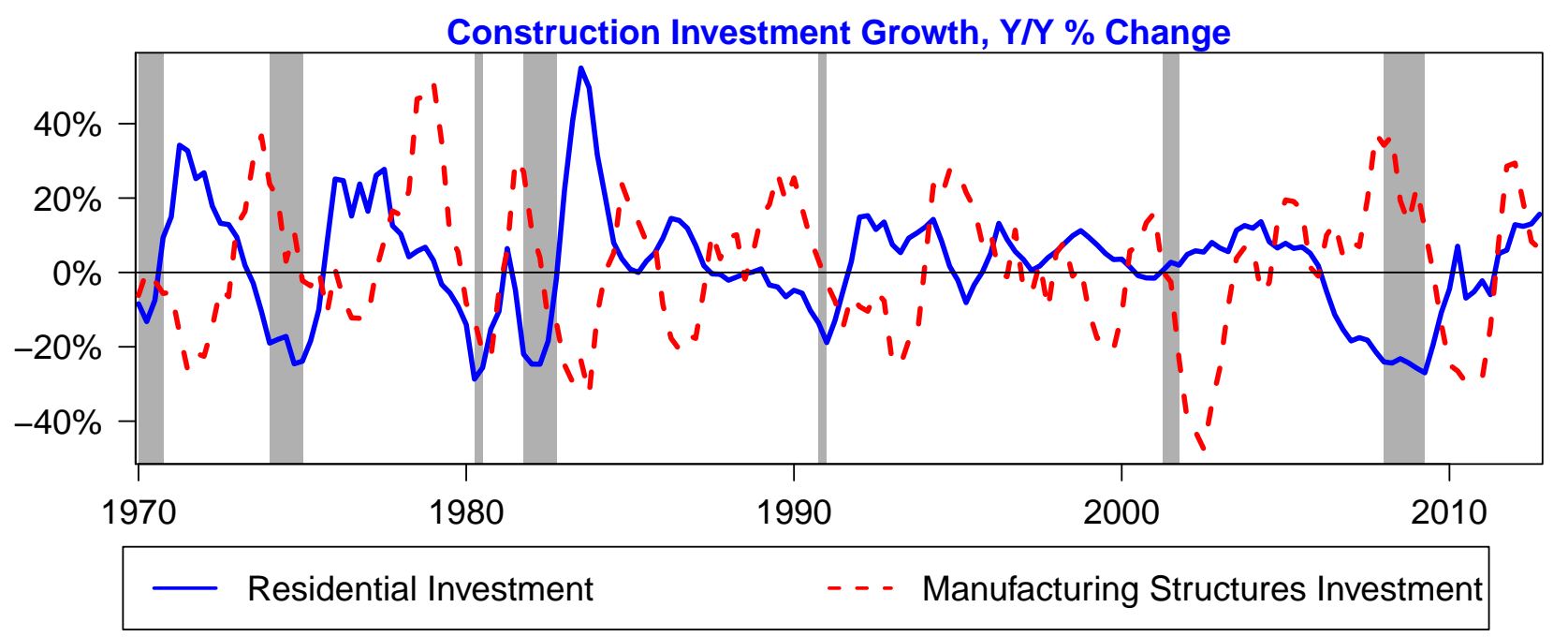

Figure 4: Residential and Manufacturing Structures Investment

Note: This figure shows the year-over-year percent change in the NIPA quarterly measures of real investment in residential and manufacturing construction. Shaded areas indicate recessions.

The inverse relationship between manufacturing and residential construction activity growth can also be seen in the responses to monetary shocks in the top row of Figure 5. While residential investment falls by about $6.5 \%$ before returning to its baseline level, there is a much more muted effect in nonresidential structures investment. This is largely driven by manufacturing structures investment, which increases by up to $7.7 \%$. Residential investment averaged about $58 \%$ of total structures investment from 1970-2008, meaning construction costs such as wages and building materials are driven to a large degree by activity in the housing market. This can be seen in the 
bottom row of Figure 5, which shows the responses of construction employment, real building $\operatorname{costs}^{4}$, and the NIPA real manufacturing structures price deflator. These measures show that the cost of construction falls significantly in the wake of contractionary monetary shocks and can explain why manufacturing firms increase their investment expenditure in response.
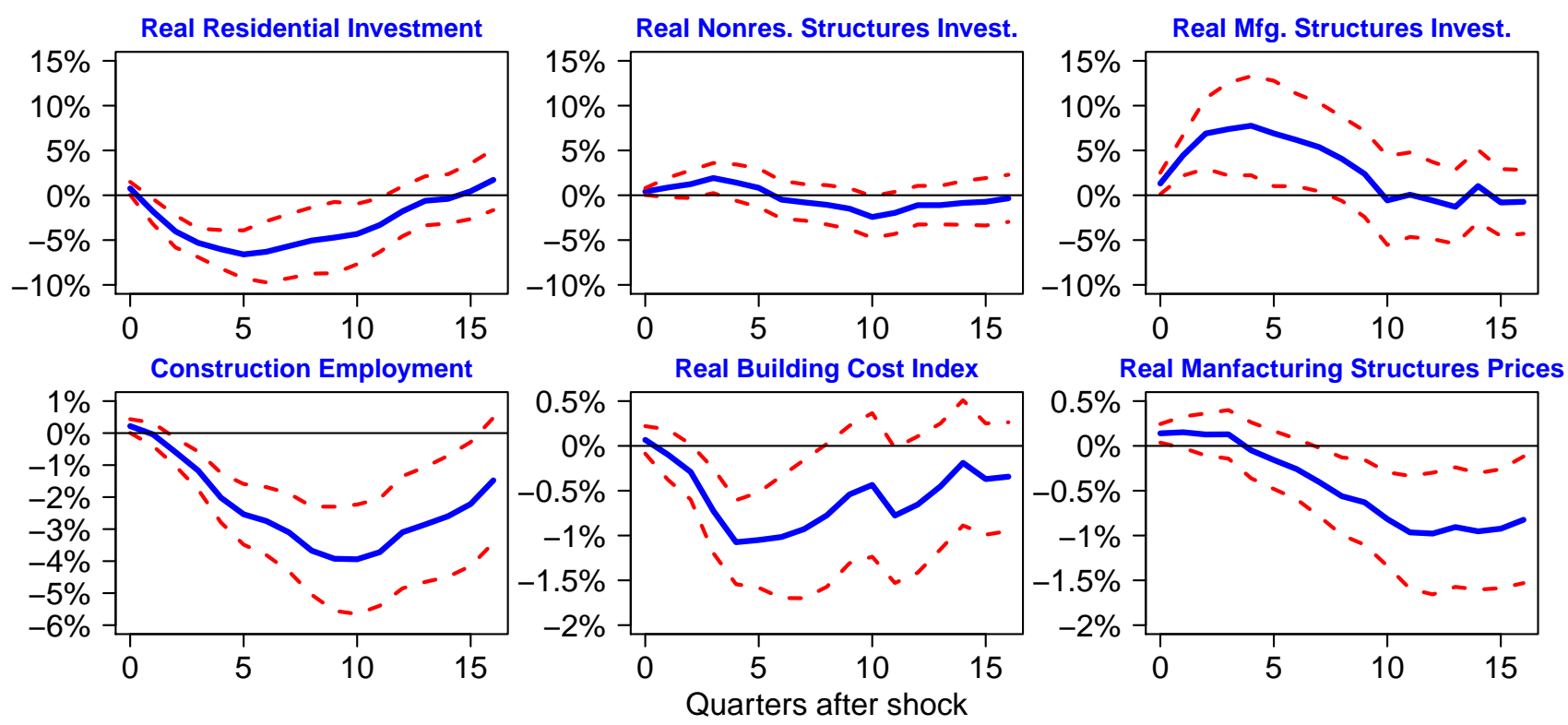

- Coefficient estimate - - +/-1.65 SE

Figure 5: Empirical Responses to 100bp Contractionary MP Shock (90\% CI)

Note: Real residential investment, real nonresidential structures investment, and real manufacturing structures investment data come from the NIPA. Construction employment data are from the BLS establishment survey (CES). The Real Building Cost Index is calculated by dividing the nominal building cost index calculated by the Engineering News-Record, which is based on measures of material and labor costs, by the GDP price index. Real manufacturing structures prices are calculated by dividing the NIPA price index for manufacturing structures investment by the GDP price index. The estimating equation has the same structure and number of lags as Equation 1 but does not include lags of industry sales growth or the share of durable sales. Regressions include shocks from 1970-2004 and outcomes through 2008.

Building permit data allow for analysis of structures investment at the "project" level. Dodge Analytics is a consulting firm that collects commercial building permits based on county-level filings. They generously shared aggregate data on commercial building permits dating back to 1967 for the total number and value of new (defined as those with a planned start date within 60 days) building permits split by type of structure. The results for manufacturing structures are shown in Figure 6.

The leftmost panel shows that the number of new permits is strongly procyclical, declining by about $4 \%$ before returning to its pre-shock level over four years. The total value of the projects,

\footnotetext{
${ }^{4}$ This measure is the Engineering News-Record's Building Cost Index, which is calculated based on a variety of wages and materials in the construction industry and deflated using the GDP price index.
} 
shown in the middle panel, closely matches the shape of the response of the NIPA measure of manufacturing construction value by increasing for about two years. The right panel confirms that the average project size is strongly countercyclical. To the extent that bigger firms build more valuable structures, these findings are consistent with those from the previous section showing that the largest firms are able to take advantage of the decline in prices by increasing their investment. The next section shows that the procyclical movement in the cost of investment is not limited to structures.
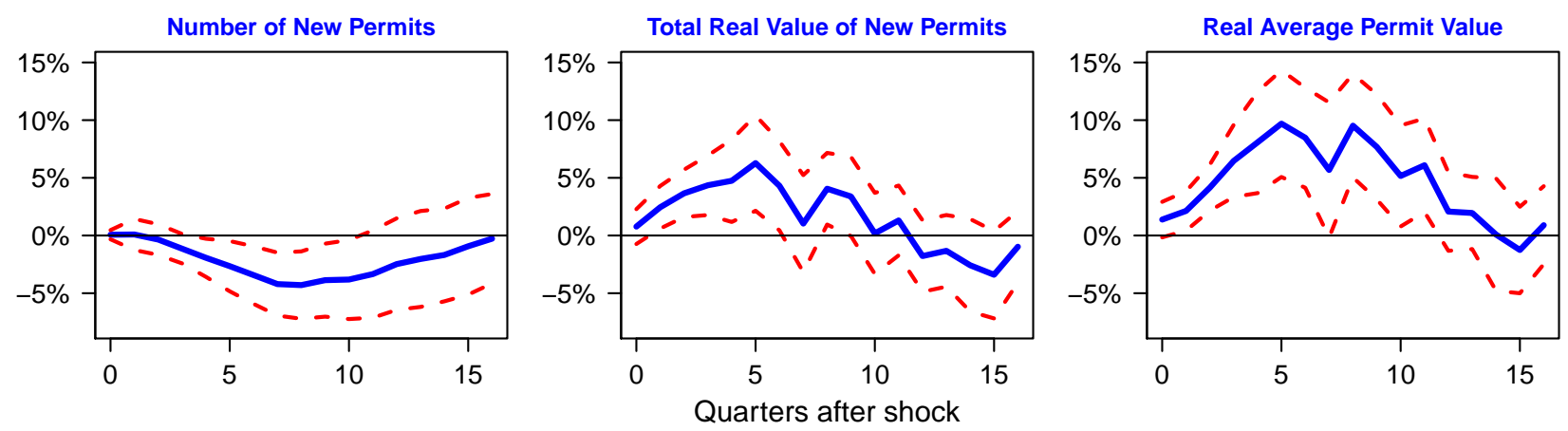

Coefficient estimate $\quad-\quad+/-1.65$ SE

Figure 6: Empirical Responses to 100bp Contractionary MP Shock (90\% CI)

Note: Building permit data were provided by Dodge Analytics. New permits are defined as those with a planned start date of within 60 days. Only permits for manufacturing structures are included in the regression. The real value of all permits is obtained by deflating the nominal value by the manufacturing structures investment price index. The real average permit value is obtained by dividing the real value of new permits by the number of new permits. The estimating equation has the same structure and number of lags as Equation 1 but does not include lags of industry sales growth or the share of durable sales. Regressions include shocks from 1970-2004 and outcomes through 2008.

\subsection{User Costs and Monetary Policy}

Investment decisions should take into consideration not just relative prices but also other factors such as depreciation, financial frictions, and expected price dynamics. If firms rent their capital then equilibrium rental rates should encapsulate all of this information. In a more realistic setting in which firms own their capital and rental rates are not observed, a more structural approach is necessary to back out the determinants of investment.

Deriving an empirical estimate of this implicit rental rate (known as the user cost of capital) is the driving question behind a large literature which dates back to Hall and Jorgenson (1967) and includes more recent examples such as Chirinko et al. (1999). In a structural model a firm's first order condition on capital accumulation can be rearranged so that the marginal product of capital is isolated. The terms on the other side comprise the user cost and can be interpreted as 
the real per-period cost of investment. For example, in a neoclassical setting the user cost $U C_{t}$ can be written as follows:

$$
U C_{t}=\frac{P_{t}^{I}}{P_{t}^{Y}}\left[i_{t}+\delta_{t}-E_{t} \Delta P_{t+1}^{I}\right]
$$

$P_{t}^{I}$ and $P_{t}^{Y}$ are the prices of investment and output, $i_{t}$ is the gross interest rate, $\delta_{t}$ is the depreciation rate, and $E_{t} \Delta P_{t+1}^{I}$ is the expected change in the price of investment. In this setting firms will increase their investment if: 1) the relative price of investment falls, 2) the expected price of future investment rises, or 3) interest rates decline. I calculate interest rates and depreciation for manufacturing firms from the QFR, with total interest payments as a share of total debt representing the interest rate and depreciation as a share of the capital stock as the depreciation rate.

In the absence of data on expected investment prices I consider four alternative empirical specifications. In my baseline specification in the leftmost panel of Figure 7, I use lagged changes in investment prices as a proxy for expected future price changes. In the second panel, I use the actual one-period ahead price changes. In the third panel, I ignore expected price changes entirely by imposing $E_{t} \Delta P_{t+1}^{I}=0$. Finally, the last panel ignores interest, depreciation, and future price changes and simply calculates the change in investment prices relative to the GDP price index.

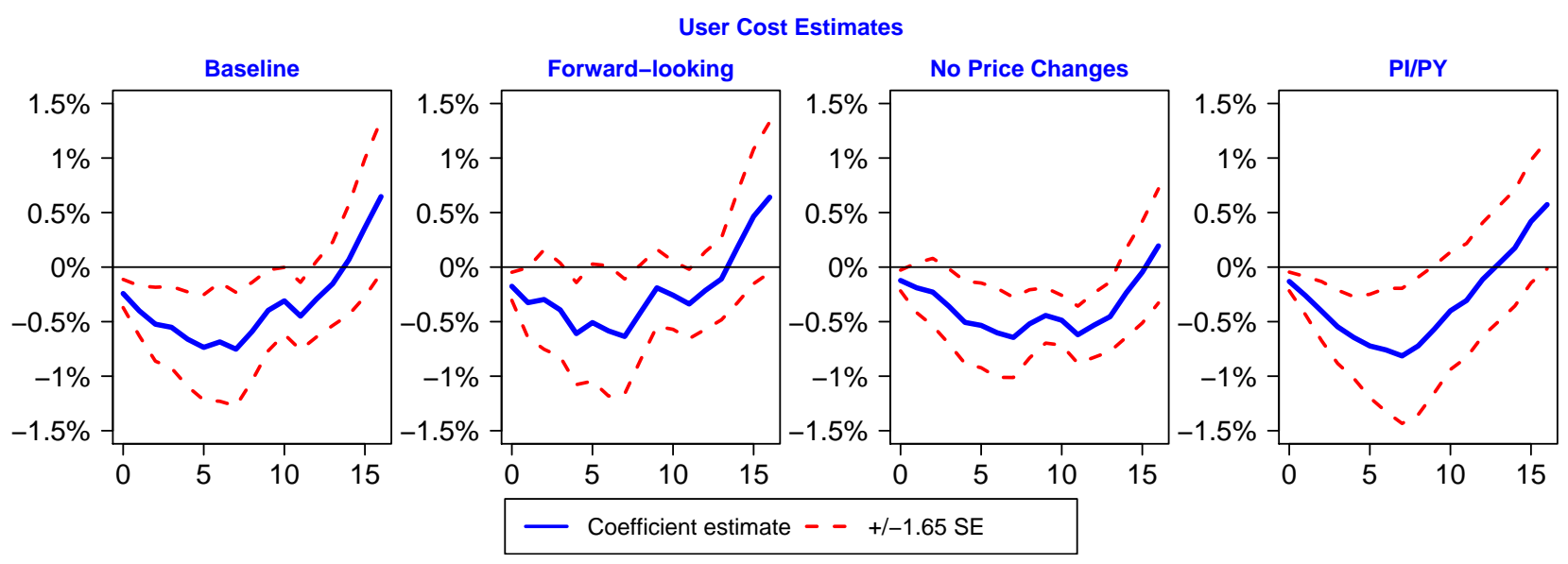

Figure 7: Empirical Responses to 100bp Contractionary MP Shock (90\% CI)

Note: All user cost calculations are based on Equation 2. All specifications use the same measures for $P_{t}^{I}$ (the nonresidential fixed investment price index), $P_{t}^{Y}$ (the BEA manufacturing output deflator), $i_{t}$ (total interest payments plus total debt dividied by total debt calculated from the QFR for the entire manufacturing sector), and $\delta_{t}$ (depreciation divided by the stock of property, plant, and equipment from the QFR for the entire manufacturing sector). The specifications differ in how they treat expected net percentage changes in the price of investment $E_{t} \Delta P_{t+1}$. The "Baseline" specification uses the previous period's percent change in $P_{t}^{I}$. The "Forward-looking" specification uses the actual one-period ahead change in $P_{t}^{I}$. The "No Price Changes" specification sets the $E_{t} \Delta P_{t+1}$ term equal to zero in all periods. The "PI/PY" specification includes only the ratio of $P_{t}^{I}$ to $P_{t}^{Y}$ and ignores interest rates, depreciation, and expected price changes. The estimating equation has the same structure and number of lags as Equation 1 but does not include lags of industry sales growth or the share of durable sales. Regressions include shocks from 1970-2004 and outcomes through 2008. 
All of these specifications show a reduction in user costs of about $0.6-0.8 \%$ in the 8 quarters following the shock. The aggregate estimates in the previous section implied an increase in the capital stock of up to $1.8 \%$, implying a back-of-the-envelope user cost elasticity of between -2 and -3 . This number is larger in magnitude than most estimates, which range between 0.5 and -1.0 according to Hassett and Hubbard (2002). A more recent estimate by Dwenger (2014), however, estimates an elasticity of around -1.3. Caballero et al. (1995), who look at plant-level investment data in manufacturing and are thus more directly applicable to my work, find industry-specific elasticities from 0 to -2 with an average around -1 and larger elasticities concentrated in nondurable industries. Thus while the elasticity implied by my results is large, it is not implausible. ${ }^{5}$ The next section shows that financial frictions can help explain why large and nondurable producers take advantage of this decline in user costs while small and durable firms do not.

\subsection{Financial Constraints}

In this section I show that durable producers are more financially constrained than nondurable producers using QFR income and balance sheet data and argue that these differences can explain the difference in investment behavior across sectors. Durable producers rely more on short-term liabilities, pay higher effective interest rates, and disburse fewer dividends. In Appendix D, I provide a more rigorous theoretical treatment based on Tirole (2010) showing that volatile demand and intertemporal production, both of which are salient features of durable manufacturing, can reduce the borrowing capacity of a firm compared to one which is otherwise identical.

While there is an extensive empirical literature that takes as given that some firms are more constrained than others ${ }^{6}$, this paper builds on a research agenda that links the durability of a firm's output to the degree of financial constraint that it faces. Rajan and Zingales (1996), for example, find that six of the eight manufacturing industries with the highest reliance on external finance are durable producers. Almeida and Campello (2007) argue that the assets of durable producers are less liquid than their nondurable counterparts, which reduces their value as collateral. Banerjee et al. (2008) show evidence that durable producers in bilateral relationships maintain lower levels of leverage than nondurable producers as a way of maintaining bargaining power to prevent holdup problems. Finally, Gomes et al. (2009) find that durable goods manufacturers have a large equity

\footnotetext{
${ }^{5}$ Most of these estimates focus on changes in user cost due to taxes, whereas the most important feature of user costs in my specification is monetary policy's effect on the relative prices of investment goods.

${ }^{6}$ See for example Fazzari et al. (1988), Kaplan and Zingales (1997), Almeida and Campello (2001), Whited and Wu (2006), Giroud and Mueller (2015), and Farre-Mensa and Ljungqvist (2016).
} 
risk premium and argue this is a fundamental consequence of the higher volatility of demand for their products. To my knowledge, this paper is the first to directly consider these effects in the context of monetary policy.

Analyzing these features requires a clear definition of what it means for a firm to be financially constrained. I define a firm as being financially constrained if it faces a convex cost of obtaining external capital. This implies that a firm's marginal cost of raising one more dollar of external funding is increasing in the amount raised. ${ }^{7}$ In the limiting case in which a firm faces an explicit cap on the quantity of funds it can raise, this curve will be vertical, but in the absence of information about such limits, this will be indistinguishable from the case in which a firm is able to raise additional funds but is deterred by the costs of doing so.

While measuring financial constraints in the data is notoriously difficult, there are several commonly cited indicators discussed in the literature. These include higher reliance on shortterm debt, a higher risk premium, more volatile cash flows, and lower dividend disbursements. Figure 8 shows that these measures all point to more binding financial constraints for durable producers relative to nondurable producers.
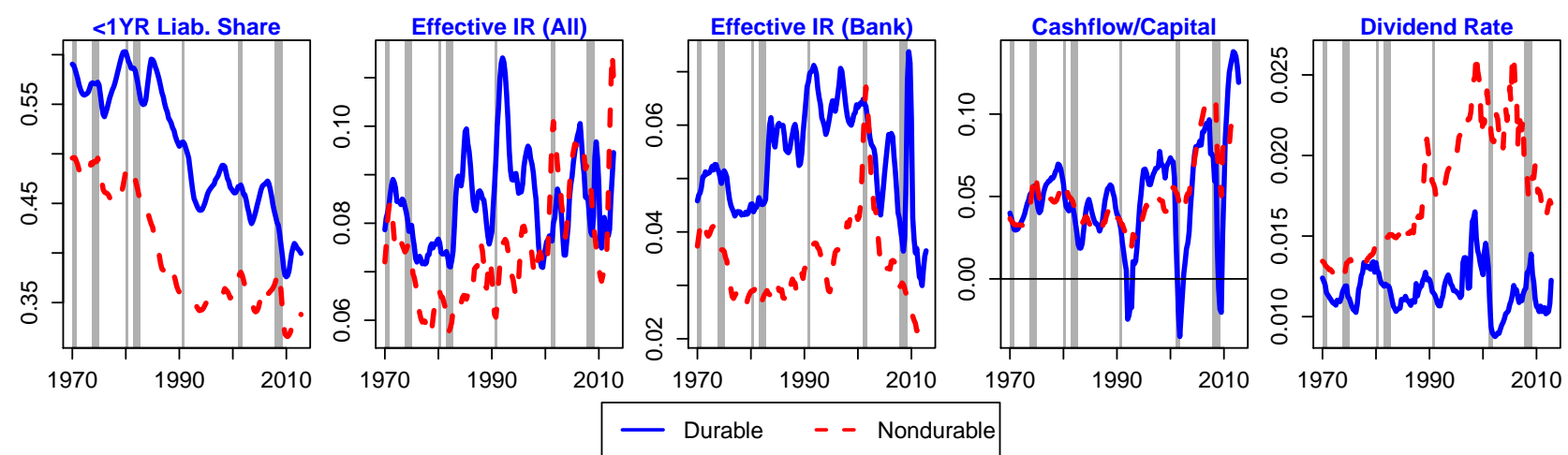

Figure 8: Financial Constraint Measures

Note: All data are calculated from the QFR. The first figure shows the ratio of each sector's aggregate debt with maturity of less than one year to its total debt. The second panel shows the aggregate average interest rate, which is defined as all debt interest payments divided by all debt. The third panel shows the ratio of interest payments on bank debt to all bank debt. Both of these interest rate measures use only long-term debt stocks and installments because information on short-term installments is not separately available. The fourth panel shows the ratio of net income to the stock of property, plant, and equipment net of depreciation. The rightmost panel shows the ratio of dividend payments to the book value of equity. Shaded areas indicate recessions.

Durable producers have a higher share of their total liabilities with a maturity of less than one year. Past studies of the determinants of debt maturity such as Barclay and Smith (1995) and Guedes and Opler (1996) find that smaller, riskier, and more credit-constrained firms are more

\footnotetext{
${ }^{7}$ This is the definition used in Almeida and Campello (2001) and Farre-Mensa and Ljungqvist (2016).
} 
likely to rely on short-term liabilities. Despite this, the second and third panels show that durable producers generally face higher average interest rates than do nondurable producers. The total interest rate for firms in each sector $i$ can be approximately decomposed as $R_{i}=r_{f}+t p_{i}+r p_{i}$ where $r_{f}$ is an economy-wide risk-free rate and $t p_{i}$ and $r p_{i}$ are sector-specific term and risk premia. The higher reliance on short-term liabilities for durable producers suggests their average term premium should be lower $\left(t p_{D}<t p_{N}\right)$. This in turn implies that their higher interest rates are driven by a higher risk premium, a finding which is in line with those of Gomes et al. (2009).

Cash flows, shown in the fourth panel, offer further evidence durable producers face a higher risk premium on their debt. Not only is cash flow more volatile for durable producers, but the fluctuations are asymmetric in magnitude; while there is a small period in the mid-90s in which the ratio was slightly higher for durable producers, it is far lower during the most recent three recessions. Another commonly cited indicator of financial constraint in the finance literature (including Whited and $\mathrm{Wu}(2006)$ ) is the ability of a firm to pay dividends. If firms face a premium to obtain outside financing, it will raise the real value of internal funds relative to dividend disbursements. The rightmost panel shows that the dividend payout ratio is consistently lower for durable producers, particularly since the mid-1980s. Figure 9 shows the breakdown for large firms across sectors and compares them to all small firms, suggesting these differences are not driven solely by different distributions of firm size across sectors.
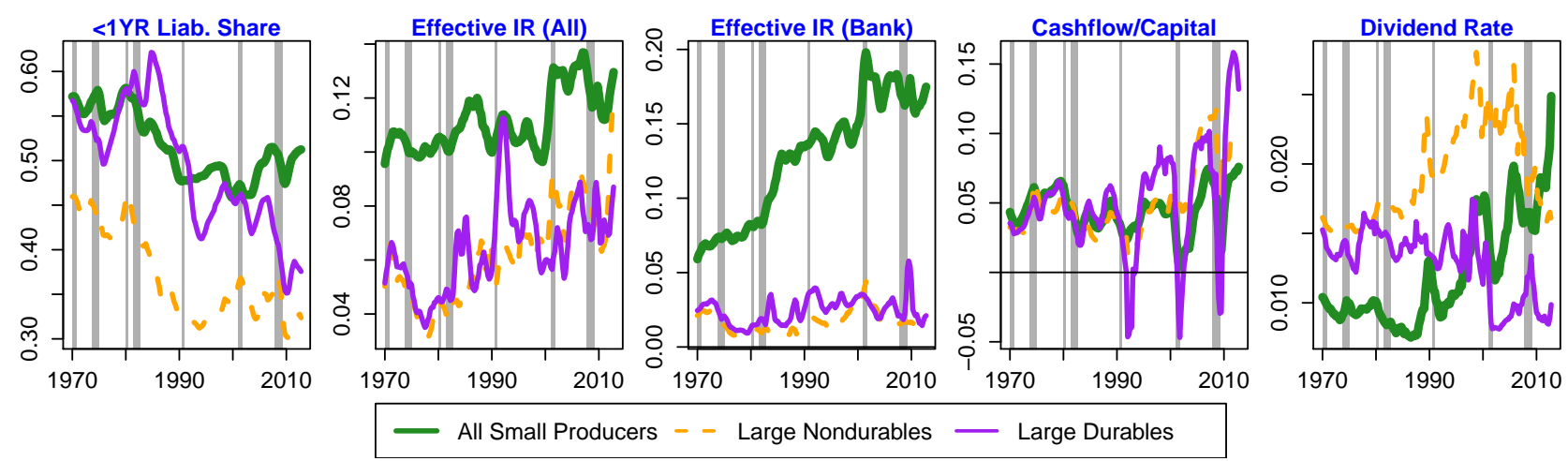

Figure 9: Financial Constraint Measures

Note: All data are calculated from the QFR. Large firms are defined as those with at least $\$ 1$ bn in assets. The first figure shows the ratio of each sector's aggregate liabilities with maturity of less than one year to its total liabilities. The second panel shows the aggregate average interest rate, which is defined as all debt interest payments on debt divided by all debt. The third panel shows the ratio of interest payments on bank debt to all bank debt. Both of these interest rate measures use only long-term debt stocks and installments because information on short-term installments is not separately available. The fourth panel shows the ratio of net income to the stock of property, plant, and equipment net of depreciation. The rightmost panel shows the ratio of dividend payments to the book value of equity. Shaded areas indicate recessions.

Large durable producers still pay higher average interest rates than large nondurable producers 
despite relying more on short-term liabilities. Large durable producers also have more volatile cash flows and pay fewer dividends. These findings imply that differences in the financial frictions faced across sectors obtain even conditional on firm size. It also suggests a hierarchy of financial constraint. Large durable producers appear to be more financially constrained than nondurable producers, and small firms are more constrained than either type of large firm.

Information about the time it takes to produce in each sector provides further evidence for heterogeneity in financial constraints, as long production schedules can distort the link between production and cash flow. Figure 10 shows the share of total manufacturing inventories in each sector broken down by stage of production: raw materials, works in progress (WIP), or finished goods. While both types of manufacturers have broadly similar raw material shares at any given time, there are substantial differences in WIP and finished inventory shares. Durable producers have roughly $40 \%$ of their inventories as WIP compared to $15-20 \%$ for nondurable producers. This difference is flipped in the finished inventory share, which is much higher for nondurable producers. While there is minor cyclical variation, these ratios are relatively stable over time, suggesting that they are inherent features of the goods being produced.

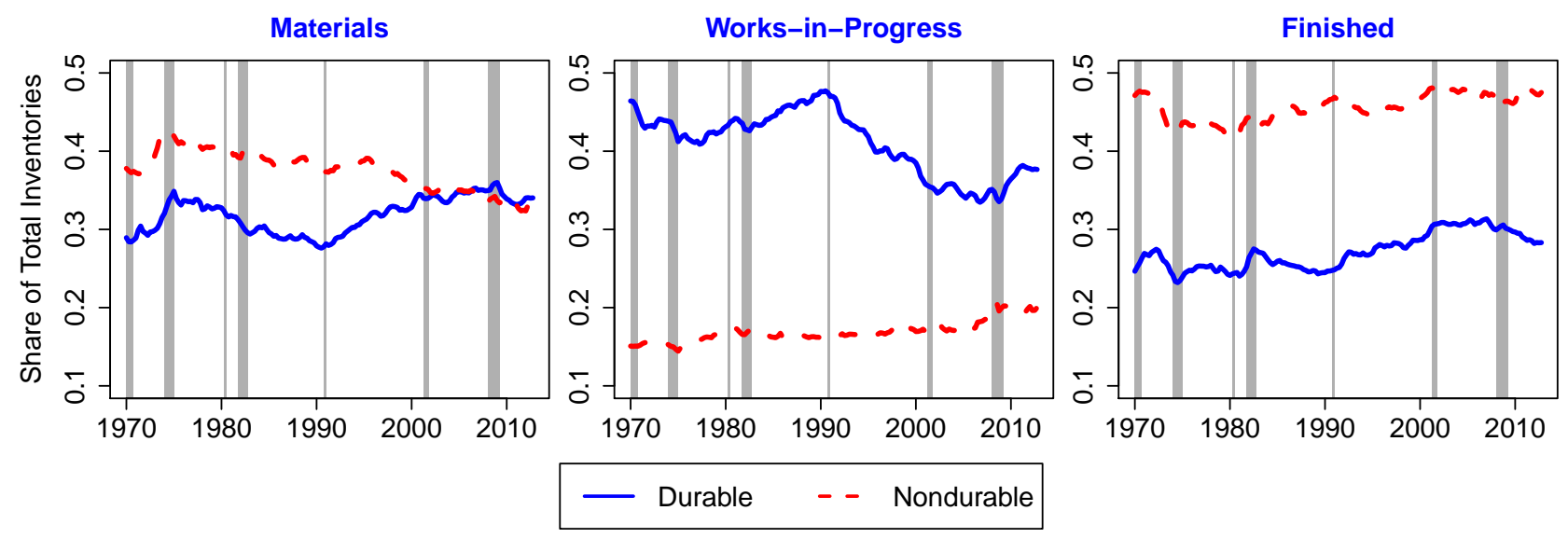

Figure 10: Manufacturing Inventory Shares

Note: Each panel shows the ratio of the value of each type of inventory relative to the total value of inventories for each sector. Data are from the Census Bureau's Manufacturer's Shipments, Inventories, and Orders (M3) survey and are exhaustive such that the three shares add up to one (subject to rounding error). While the QFR data do report an aggregate inventory measure as a balance sheet item, the survey does not ask respondents to distinguish between different types of inventories. Shaded areas indicate recessions.

Models that generate a need for finance through asymmetric information usually do not allow first-best levels of investment. ${ }^{8}$ To the extent that volatility of cash flow or time to build

\footnotetext{
${ }^{8}$ Holmstrom and Tirole (1997), who use moral hazard, and Kiyotaki and Moore (1997), who use incomplete contracts, are two elegant examples of this approach.
} 
can exacerbate these information frictions, durable producers should be more financially constrained in these settings. These mechanisms and their implications are discussed in more detail in Appendix D. In the next section, I extend my analysis to manufacturing firms in Compustat.

\section{Evidence from Microdata}

The previous section showed the effects of monetary shocks on the aggregate capital stock of the manufacturing sector. I found that contractionary shocks led to increases in investment and that this increase is driven by large firms and those in the nondurable sector. To explain these features I showed that the aggregate user cost of capital fell and provided suggestive evidence that financially unconstrained firms were able to take advantage of the cyclical drop in prices. In this section I use quarterly firm-level data from Compustat to show that the manufacturing capital stock increases in response to contractionary monetary policy not just in the aggregate, but also in the cross section. The increases in investment are even stronger for these publicly traded manufacturing firms than for the aggregate measures from the QFR, suggesting that financial constraints are important for these investment dynamics.

\subsection{Panel Selection and Summary Statistics}

I construct the panel from Compustat in a similar manner to Ottonello and Winberry (2018) and Jeenas (2018). The main variable of interest in my regressions is the change in the log of a firm's real capital stock net of depreciation, which matches as closely as possible the definition used in the QFR data. The full details of the data construction can be found in Appendix A. The summary stats for several major variables of interest are broken down for all manufacturing firms in the sample along with splits for durable and nondurable manufacturers in Table 1.

\begin{tabular}{||c|cc|cc|cc||}
\hline & \multicolumn{2}{|c|}{ All Manufacturing } & \multicolumn{2}{c|}{ Durable } & \multicolumn{2}{c||}{ Nondurable } \\
Variable & $\Delta k_{t}$ & Assets & $\Delta k_{t}$ & Assets & $\Delta k_{t}$ & Assets \\
\hline Mean & 0.008 & $\$ 2,316.97$ & 0.006 & $\$ 1,644.42$ & 0.009 & $\$ 2,700.32$ \\
Median & -0.005 & $\$ 233.26$ & -0.007 & $\$ 173.76$ & -0.004 & $\$ 301.21$ \\
Std. Dev. & 0.115 & $\$ 9,345.04$ & 0.104 & $\$ 6,967.98$ & 0.120 & $\$ 10,469.59$ \\
\hline
\end{tabular}

Table 1: Summary Statistics for Manufacturing Firms in Compustat

Note: These statistics cover only manufacturing firms in Compustat. All variables are deflated using the GDP price index and expressed in millions of 2009 dollars. $\Delta k_{t}$ refers to the change in the log level of real property, plant, and equipment net of depreciation (NPPE). Statistics for changes in NPPE are calculated across all firm-quarters while the ones for assets are calculated as the time average of the cross sectional value in each quarter. 


\subsection{Baseline Panel Regressions}

I use the following as my baseline specification:

$$
\Delta k_{j, t+h}=\alpha_{j, h}+\alpha_{c q, h}+\alpha_{f q, h}+\Gamma Z_{t-1}+\Omega Y_{t-1}+\sum_{k=1}^{4} \sigma_{h, k} \epsilon_{t-k}^{m}+\beta_{h} \epsilon_{t}^{m}+\nu_{j, t+h}
$$

$\Delta k_{j, t+h}$ is the change in the log of the real capital stock between time $t$ and time $t+h$ so that $h=0$ corresponds to the same quarter at which the shock hits and $h=16$ corresponds to four years after. $\epsilon_{t}^{m}$ is the same R\&R-style monetary policy shock used in Section 2. In line with my aggregate specification, I also include several lags of the shock. $\alpha_{j, h}$ is a firm fixed effect, $\alpha_{c q, h}$ is a calendar quarter fixed effect, $\alpha_{f q, h}$ is a fiscal quarter fixed effect, $Z_{t-1}$ is a vector of firmlevel controls including normalized leverage, log assets, and sales growth, and $Y_{t-1}$ is a vector of lagged aggregate controls including CPI inflation, GDP growth, and the unemployment rate. The estimates of $\beta_{h}$ for all horizons up to $h=16$ are shown in Figure 11 with $90 \%$ confidence intervals for durable, nondurable, and all manufacturing firms. In Appendix B I show that my results are robust to a variety of shock identification strategies and time horizons, including several measures of high-frequency monetary shocks which do not start until the 1990s.

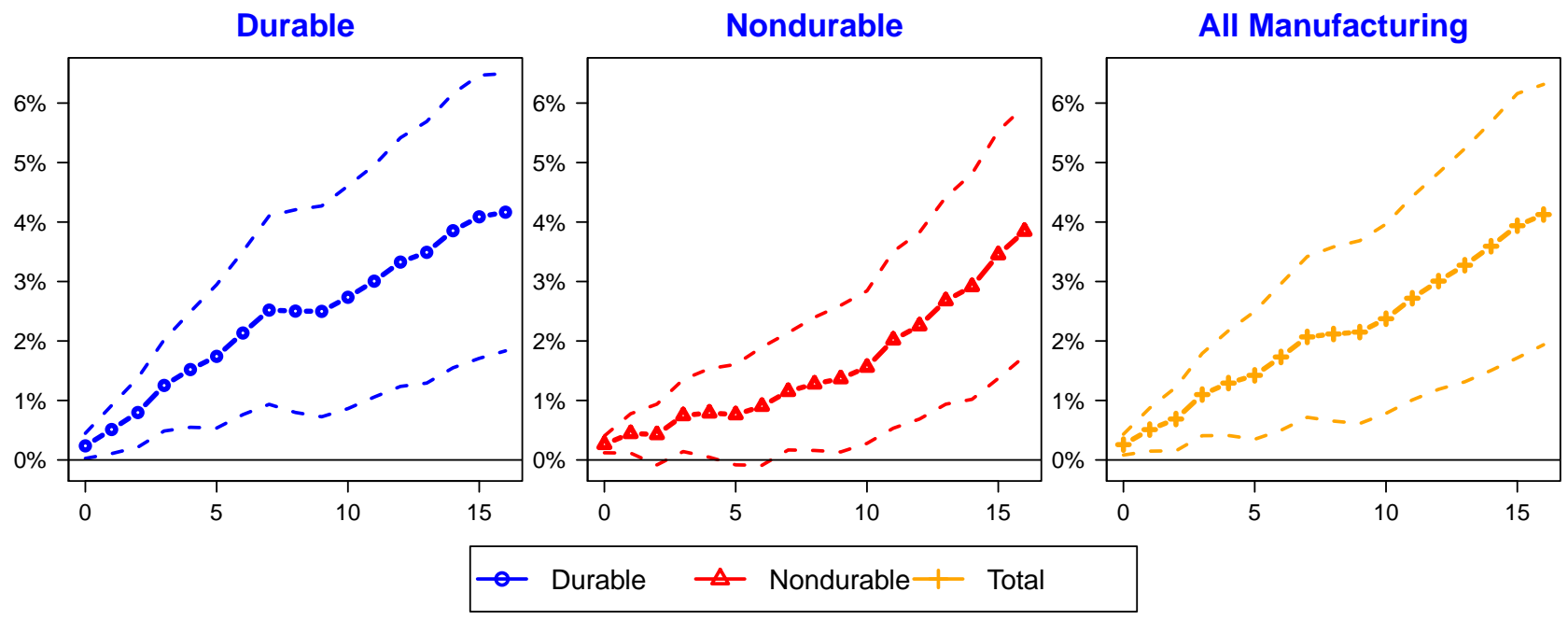

Figure 11: Empirical Capital Stock Responses to 100bp Contractionary MP Shock

Note: Impulse responses correspond to the estimates of $\beta_{h}$ from Equation 3. 90\% confidence intervals are calculated using Driscoll-Kraay standard errors. Regressions include shocks from 1975-2004 and outcomes through 2008. NPPE stocks are deflated using the nonresidential fixed investment price deflator.

The coefficient estimates are positive and highly significant throughout most of the four years 
following the shock, with a peak increase of around $4 \%$ for the total manufacturing sector by the end of the response horizon. The peak response for both the durable and nondurable sectors is similar to the aggregate.

In contrast to the QFR data, the average durable manufacturer in the Compustat data shows an increase in its investment activity. There are several distinctions between the QFR and Compustat samples that can explain this discrepancy. The most important is that publicly traded firms are less likely to be financially constrained, and there is imperfect overlap between the large firms in the QFR and those in Compustat (many of which have assets that fall below the QFR threshold for "large" firms). Second, the industry classification system can vary by source. While in principle both the Census Bureau and Compustat use a system based on revenues by source, there is no guarantee that these measures overlap, particularly for large conglomerates with many products and sources of revenue. Another possible source of difference is that Compustat is only reporting the average result; to the extent that these effects are disproportionately focused on a small set of firms, the average will not necessarily be a good approximation for the aggregate. Finally, the QFR data report only domestic assets, while Compustat includes foreign assets; these distinctions are most likely to be relevant for large multinational firms.

In conjunction with the results from the previous section, the findings from this section have important implications about the relationship between investment and financial constraints. In an economy with both financially constrained and unconstrained firms, it is not obvious ex ante which of the two types of firms should drive aggregate investment dynamics in response to monetary policy shocks. Financial constraints act to increase the marginal cost of investment, which suggests that unconstrained firms should have more flexibility and thus be more responsive. On the other hand, if contractionary monetary policy shocks exacerbate constraints through either the intensive margin (by increasing the severity of the constraint) or the extensive margin (by increasing the number of constrained firms), then these effects can dominate and financially constrained firms will drive aggregate investment behavior. My findings suggest that the former is the stronger mechanism and is in line with recent evidence using microdata, such as Ottonello and Winberry (2018) and Jeenas (2018), who find that it is the least financially constrained firms whose investment responds most to monetary policy shocks.

While my results rely on the publicly available aggregate QFR data and Compustat, they are generally consistent with the findings in Crouzet and Mehrotra (2018), who use the QFR microdata to analyze how financial constraints affect firm-level responses to monetary shocks. The exercise they conduct that is closest to my work involves analyzing the average responses for different types of firms relative to the start of a recession. They find that large firms, firms 
with bond market access, and dividend-paying firms all increase their investment relative to the start of the recession; in contrast, investment falls for small firms, those without bond market access, and firms which don't pay dividends. This is confirmed by their regressions which directly estimate investment cyclicality relative to GDP with a variety of financial constraint interaction terms; these regressions show that the correlation is consistently negative for the least constrained firms. Their panel regressions estimate that the average QFR firm decreases its investment in response to contractionary monetary shocks, but they use interactions between industries and monetary shocks in their specification. To the extent that my results are driven by the distinction between durable and nondurable producers, these interaction terms could explain this estimated decline. Even with this specification, they estimate that firm-level manufacturing investment is countercyclical using high-frequency shocks that start in the 1990s for both the QFR and Compustat, which is in line with my results.

\section{Model}

In this section I develop a model that can match the empirical findings in Sections 2 and 3. In light of the findings outlined previously, the key feature is that durable goods producers are financially constrained. In response to a contractionary monetary policy shock, the flexibility of pricing for durable producers causes the relative price of durables to fall. Durable producers and borrower households are constrained and are unable to take advantage of these lower prices, while nondurable producers and saver households increase their durable purchases. The result is a model which can qualitatively match the responses of durable goods for both consumers and producers to monetary shocks.

\subsection{Households}

The households in the model are based on those in Chen and Liao (2014). Measure $\omega$ are savers with discount factor $\beta_{S}$, while measure $(1-\omega)$ are borrowers with discount factor $\beta_{B}$. Savers are more patient $\left(\beta_{S}>\beta_{B}\right)$, which allows for borrowing in the steady state, and are endowed with ownership of the firms. Households of type $i \in\{S, B\}$ maximize utility over nondurable consumption $C_{i, t}^{N}$, stocks $D_{i, t}$ and flows $C_{i, t}^{D}$ of durable consumption, labor $H_{i, t}$, and nominal bond holdings $B_{i, t}$.

To help the model generate more realistic dynamics, I subject households to two additional frictions. The first is nondurable consumption habit formation in the manner of Fuhrer (2000). 
The second is real wage rigidity as in Blanchard and Galí (2007), where real wages are weighted averages of past real wages and consumers' current marginal disutility of labor times a markup (which helps prevent the real wage from dropping below the marginal disutility of labor). These mechanisms lead to smoother and more persistent model dynamics in response to shocks, but none of the main results in the paper depend on them.

$$
U\left(C_{i, t}^{N}, D_{i, t}\right)=\sum_{t=0}^{\infty} \beta_{i}^{t}\left[\eta \log \left(C_{i, t}^{N}-h C_{i, t-1}^{N}\right)+(1-\eta) \log \left(D_{i, t}\right)-\kappa_{i} \frac{N_{i, t}^{1+\chi}}{1+\chi}\right]
$$

I normalize relative prices in each period such that $\left(p_{t}^{N}\right)^{\eta}\left(p_{t}^{D}\right)^{1-\eta}=1$. The budget constraints are identical except for the inclusion of profits in the budget of savers.

$$
\begin{gathered}
p_{t}^{N} C_{B, t}^{N}+p_{t}^{D} C_{B, t}^{D}+B_{B, t}=\frac{\left(1+i_{t-1}\right) B_{B, t-1}}{\Pi_{t}}+w_{t}^{D} H_{B, t}^{D}+w_{t}^{N} H_{B, t}^{N} \\
p_{t}^{N} C_{S, t}^{N}+p_{t}^{D} C_{S, t}^{D}+B_{S, t}=\frac{\left(1+i_{t-1}\right) B_{S, t-1}}{\prod_{t}}+w_{t}^{D} H_{S, t}^{D}+w_{t}^{N} H_{S, t}^{N}+\frac{1}{\omega}\left(\text { Profits }_{t}\right)
\end{gathered}
$$

Durable goods accumulate according to a standard law of motion:

$$
D_{i, t}=C_{i, t}^{D}+\left(1-\delta^{D}\right) D_{i, t-1}
$$

Households are constrained in that they can only borrow up to some exogenous share $m$ of the value of their stock of durable goods. This constraint will bind in the steady state for borrowers but not savers due to the difference in discount factors.

$$
\left(1+i_{t}\right) B_{B, t}=p_{t}^{D} D_{B, t} m
$$

Let $\psi_{t}$ be the Lagrange multiplier on the borrowing constraint and $\lambda_{i, t}$ be the multiplier on the budget constraint. The household FOCs are as follows:

$$
\begin{gathered}
\eta\left(\frac{1}{C_{i, t}^{N}-h C_{i, t-1}^{N}}-h \beta_{i} E_{t}\left[\frac{1}{C_{i, t+1}^{N}-h C_{i, t}^{N}}\right]\right)=\lambda_{i, t} p_{t}^{N} \\
w_{t}=\left(\frac{\nu_{i} H_{i, t}^{\chi}}{\lambda_{i, t}}\left(1+\mu^{w}\right)\right)^{1-\rho_{w}}\left(\frac{w_{t-1}}{\Pi_{t}}\right)^{\rho_{w}} \\
\lambda_{S, t} p_{t}^{D}=\frac{(1-\eta)}{D_{t}}+\beta_{S} E_{t}\left[\lambda_{S, t+1} p_{S, t+1}^{D}\left(1-\delta_{D}\right)\right] \\
\lambda_{B, t} p_{t}^{D}=\frac{(1-\eta)}{D_{t}}+\beta_{B} E_{t}\left[\lambda_{B, t+1} p_{B, t+1}^{D}\left(1-\delta_{D}\right)\right]+m \psi_{t} p_{t}^{D} \lambda_{B, t}
\end{gathered}
$$




$$
\begin{aligned}
\lambda_{S, t} & =\beta_{S}\left(1+i_{t}\right) E_{t}\left[\frac{\lambda_{S, t+1}}{\Pi_{t+1}}\right] \\
\left(1+i_{t}\right) \psi_{t} & =1-\beta_{B} E_{t}\left(\frac{\left(1+i_{t}\right) \lambda_{B, t+1}}{\lambda_{B, t} \Pi_{t+1}}\right)
\end{aligned}
$$

If the constraint doesn't bind, $\psi_{t}=0$ and the conditions look the same for both borrowers and savers. If $\psi_{t}>0$, then the decisions of borrowers are distorted in two ways. First, the marginal value of one dollar today will be greater than the discounted expected marginal value of a dollar tomorrow. Second, borrowers will receive an additional benefit to buying durable goods because they will ease the borrowing constraint.

\subsection{Firms}

Each firm produces according to a standard Cobb-Douglas production technology and has a law of motion for capital subject to "second-order" adjustment costs in the manner of Christiano et al. (2005):

$$
\begin{gathered}
Y_{j, t}=A_{t} K_{j, t}^{\alpha^{j}} H_{j, t}^{1-\alpha^{j}} \\
K_{j, t+1}=\left(1-\delta_{K}\right) K_{j, t}+I_{j, t}\left[1-\frac{\theta_{j}}{2}\left(\frac{I_{j, t}}{I_{j, t-1}}-1\right)^{2}\right]
\end{gathered}
$$

Nondurable firms are unconstrained and have standard first order conditions, with marginal cost $m c_{t}^{N}$ :

$$
\begin{gathered}
w_{t}=\left(1-\alpha^{N}\right) A_{t} K_{N, t}^{\alpha_{N}} H_{N, t}^{-\alpha^{N}} m c_{t}^{N} \\
p_{t}^{D}=\beta_{S} E_{t}\left[\left(\frac{\lambda_{S, t+1}}{\lambda_{S, t}}\right)\left\{A_{t+1} m c_{t+1}^{N} \alpha^{N} K_{N, t+1}^{\alpha^{N}-1} H_{N, t+1}^{1-\alpha^{N}}+p_{t+1}^{D}\left(1-\delta_{K}\right)\right\}\right]
\end{gathered}
$$

Durable goods producers face an intratemporal working capital constraint. Their purchases of labor and investment are constrained to be an exogenous share $\xi$ of the value of their stock of durable goods.

$$
w_{t}^{D} H_{t}^{D}+p_{t}^{D} I_{t}^{D}=\xi p_{t}^{D} K_{t}^{D}
$$

Let $\mu_{t}$ be the Lagrange multiplier on the durable firm financial constraint. Then the optimality conditions for the durable firm's choice of inputs are: 


$$
\begin{gathered}
w_{t}\left(1+\mu_{t}\right)=\left(1-\alpha^{D}\right) A_{t}\left(K_{t}^{D}\right)^{\alpha^{D}}\left(H_{t}^{D}\right)^{-\alpha^{D}} m c_{t}^{D} \\
p_{t}^{D}\left(1+\mu_{t}\right)=m k_{t}^{D} \\
m k_{t}^{D}=\beta_{S} E_{t}\left[( \frac { \lambda _ { S , t + 1 } } { \lambda _ { S , t } } ) \left(\alpha^{D} m c_{t+1}^{D} A_{t+1}\left(K_{t+1}^{D}\right)^{\alpha^{D}-1}\left(H_{t+1}^{D}\right)^{1-\alpha^{D}}\right.\right. \\
\left.\left.+m k_{t+1}^{D}\left(1-\delta_{K}\right)+p_{t+1}^{D} \mu_{t+1} \xi\right)\right]
\end{gathered}
$$

If the constraint binds, $\mu_{t}>0$ and durable producers face an effective wedge on their input prices relative to nondurable producers. In addition to increasing production, expanding their capital stock also eases the working capital constraint faced by durable producers in the future.

Firms' pricing decisions are subject to Rotemberg-style convex adjustment costs, leading to the following price-setting optimality condition:

$$
\left[\left(1-\epsilon^{j}\right) p_{t}^{j}+\epsilon^{j} m c_{t}^{j}\right]-\phi^{j}\left(\Pi_{t}^{j}-1\right) \Pi_{t}^{j}+\beta_{S} \phi^{j} E_{t}\left[\left(\frac{\lambda_{S, t+1}}{\lambda_{S, t}}\right)\left(\Pi_{t+1}^{j}-1\right) \Pi_{t+1}^{j}\left(\frac{Y_{t+1}^{j}}{Y_{t}^{j}}\right)\right]=0
$$

\subsection{Equilibrium and Solution}

The market clearing conditions in the goods and borrowing markets imply:

$$
\begin{gathered}
\omega H_{S, t}^{D}+(1-\omega) H_{B, t}^{D}=H_{t}^{D} \\
\omega H_{S, t}^{N}+(1-\omega) H_{B, t}^{N}=H_{t}^{N} \\
\omega C_{S, t}^{D}+(1-\omega) C_{B, t}^{D}=C_{t}^{D} \\
\omega C_{S, t}^{N}+(1-\omega) C_{B, t}^{N}=C_{t}^{N} \\
C_{t}^{D}+I_{t}^{D}+I_{t}^{N}+\frac{\phi^{D}}{2}\left(\Pi^{D}-1\right)^{2} Y_{t}^{D}=Y_{t}^{D} \\
C_{t}^{N}+\frac{\phi^{N}}{2}\left(\Pi^{N}-1\right)^{2} Y_{t}^{N}=Y_{t}^{N} \\
\omega B_{S, t}+(1-\omega) B_{B, t}=0
\end{gathered}
$$

Finally, to close the model, I specify a standard Taylor Rule for the nominal interest rate:

$$
\beta_{S}\left(i+i_{t}\right)=\left(\beta_{S}\left(i_{t-1}\right)\right)^{\rho^{M}}\left(\Pi_{t}^{\phi_{\Pi}}\right)^{1-\rho^{M}} \exp \left(e_{t}^{M}\right)
$$


Following Monacelli (2009) and Chen and Liao (2014), I ensure that the calibration results in the constraint binding in the steady state and then linearize around that steady state, assuming that the constraint binds for small perturbations. The full set of equilibrium conditions can be found in Appendix C.

\subsection{Parameter Values and Calibration}

Most of the parameters are taken directly from Chen and Liao (2014). I use the depreciation rate for capital calculated from the QFR data and the depreciation rate for consumer durables from the BEA fixed asset tables. I impose that both types of consumers have the same labor disutility scaling parameter $\nu$ and that both types of producers have the same capital share $\alpha$ and elasticity of substitution $\epsilon$. The major addition is the parameter governing the exogenous working capital constraint $\xi$, which I set to be 0.1 . In addition to resulting in a positive value for the Lagrange multiplier $\mu$ in the steady state given the other parameter values, it is also reasonably close to the sample averages for the ratios of cash $(14.4 \%)$ and short-term bank debt $(8.2 \%)$ to the capital stock. The parameter values are summarized Table 2.

\begin{tabular}{||c|c|c||}
\hline Parameter & Value & Description \\
\hline$\beta_{S}, \beta_{B}$ & $0.99,0.98$ & Discount factors \\
\hline$\omega$ & 0.5 & Share of savers \\
\hline$\eta$ & 0.8 & Nondurable consumption share \\
\hline$\rho_{w}, \mu^{w}$ & $0.5,0.1$ & Wage rigidity and markup \\
\hline$h$ & 0.9 & Habit formation \\
\hline$\nu_{S}, \nu_{B}$ & 4 & Labor disutility scale \\
\hline$m, \xi$ & $0.7,0.1$ & Borrowing limits \\
\hline$\phi_{D}, \phi_{N}$ & $0,58.25$ & Price adjustment costs \\
\hline$\theta_{D}, \theta_{N}$ & 2 & Investment adjustment costs \\
\hline$\delta_{D}, \delta_{K}$ & $0.02,0.03$ & Depreciation rates \\
\hline$\epsilon_{D}, \epsilon_{N}$ & 11 & Substitution elasticities \\
\hline$\alpha_{D}, \alpha_{N}$ & 0.33 & Capital shares \\
\hline$\varphi_{\pi}, \rho$ & $1.5,0.9$ & Taylor Rule \\
\hline
\end{tabular}

Table 2: Parameter Values

\subsection{Results and Mechanism}

The model impulse responses for the capital stocks of producers can be seen in the left panel of Figure 12. When a contractionary monetary policy shock hits, the price of durable goods 
falls. Nondurable producers, which are unconstrained, take advantage by increasing their capital purchases. Durable producers, whose constraint is exacerbated by the decline in the value of their capital stock used as collateral, are forced to cut back. The increase in capital expenditure by the nondurable sector is larger than the decline from the durable sector, so the aggregate capital stock in the manufacturing sector rises. For comparison, the right panel shows the estimated capital stock responses from the QFR as in Figure 1. The model is able to match the empirical dynamics of the manufacturing capital stock quite well.

Model Capital stock

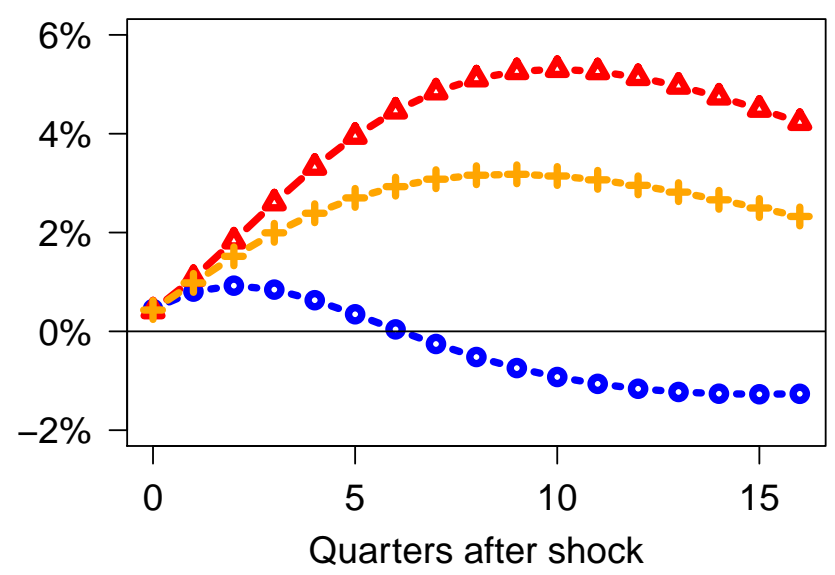

Quarters after shock $\neg$ Durable $\triangle$ Nondurable + Total

Figure 12: Model and Data Responses to Contractionary MP Shocks

Note: The left panel shows the model responses to a $100 \mathrm{bp}$ contractionary monetary shock to the capital stocks for the total manufacturing sector as well as each subsector. The right panel shows the empirical responses to a $100 \mathrm{bp}$ contractionary monetary shock shown previously in Figure 1.

The two key mechanisms through which investment increases in response to contractionary monetary shocks in this model, as in Barsky et al. (2007), are the long life of durable goods and the decline in their relative price. When a monetary shock hits, both types of producers want to cut prices. Because nondurable prices are sticky, durable producers are able to reduce their prices by a larger amount. Even small drops in the relative price are able to spur large increases in durable purchases in this model because durables are long-lived; buying the durable good at a low price today is equivalent to getting a discount on a long series of future service flows.

As a result, this drop in the relative price of durable goods is large enough to offset the decline in demand for nondurable producers and leads to them expanding their investment. The presence of financial constraints prevents durable producers from increasing investment in two 
ways. Because they are financially constrained, the fall in the relative price of durables reduces the value of their capital stock and hence the amount of money that they can borrow to fund production. In addition, durable producers experience a drop in demand from the consumer side due to the tightening of the borrowing constraints on impatient consumers that leads to a decline in aggregate household durable expenditure.

This mechanism can be seen directly by looking at the model responses of the prices of durable goods and the user cost in Figure 13. The orange line shows that the relative price of durable goods falls sharply in response to a contractionary monetary shock before ultimately rising above its pre-shock level. The red and blue lines represent the respective user costs- that is, the implicit rental rate set equal to the marginal product of capital- for the durable and nondurable producers. These expressions are complicated and include both current and expected prices, demand, adjustment costs, and, for the durable firms, degrees of financial constraint. For durable producers, the financial constraints are powerful enough to push up the user cost of capital and lead to a reduction in their capital stock.

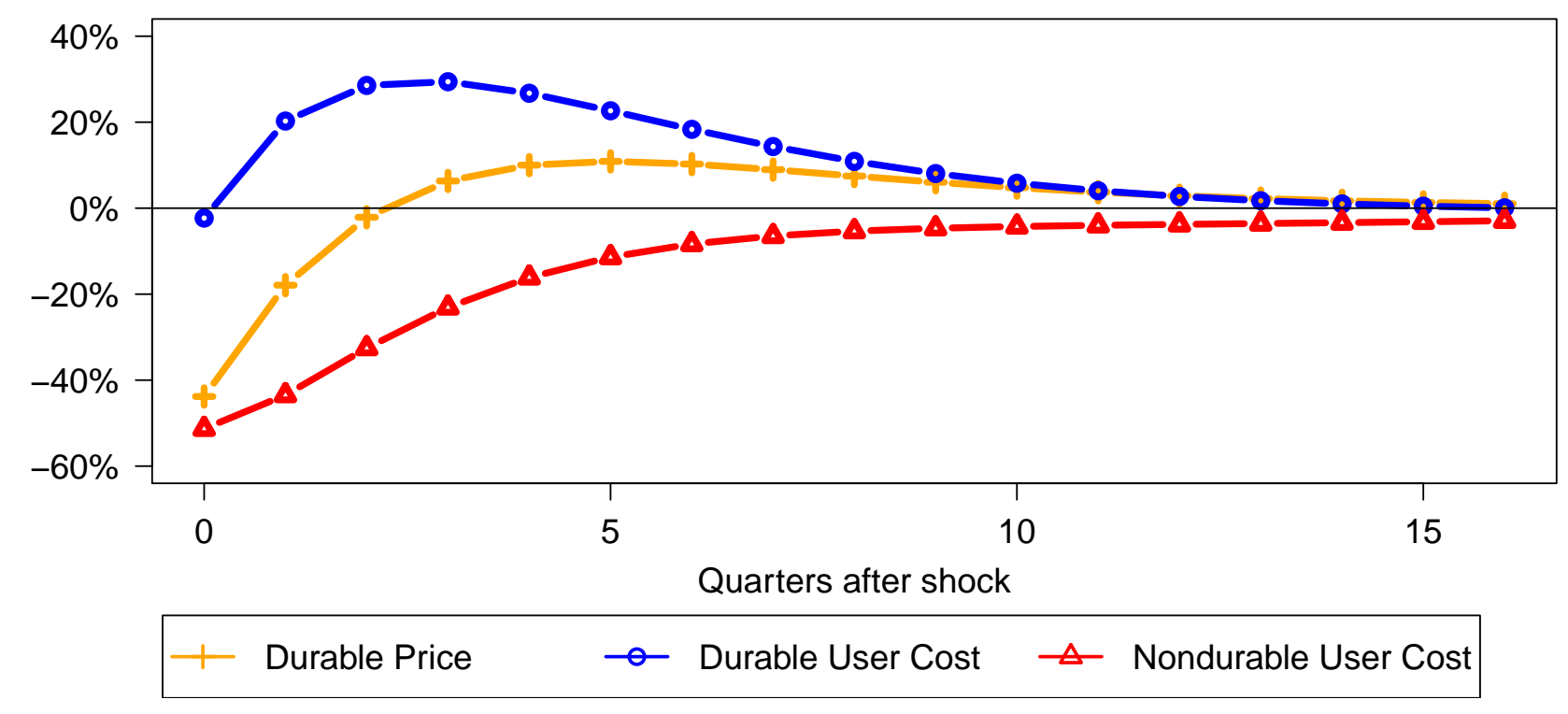

Figure 13: Model Responses to Contractionary MP Shocks

Note: This figure shows the model response to a 100bp contractionary monetary shock for the relative price of the durable good as well as the user costs for each sector. The user cost in the model can be calculated by rearranging the firm's first order condition on investment to include everything but the marginal product of capital on one side and all remaining variables- including current and expected prices, demand, and financial conditions- on the other. 


\section{Alternative Models and Investment Comovement}

The previous section showed that the model is able to generate responses to monetary shocks that are consistent with the data for both consumption and investment. These responses are summarized in Figure 14. The left column reproduces the analysis from the previous section by showing the responses of the capital stock of each type of producer in both the model (the top row) and the data (the bottom row). The right column shows the responses of nondurable consumption expenditure and the stock of consumer durable goods. The bottom-right panel shows that the responses of both nondurable consumption and the stock of durable goods decline by about $1 \%$ before returning to their pre-shock level. The model matches the responses of nondurable consumption relatively well, though with a larger peak effect. The on-impact decline in the stock of durable goods matches the peak effect seen in the data, though it recovers quickly and ends up stabilizing at a level above where it started. This is due to the combination of the persistent drop in prices and the lack of adjustment frictions on the part of consumer durables.
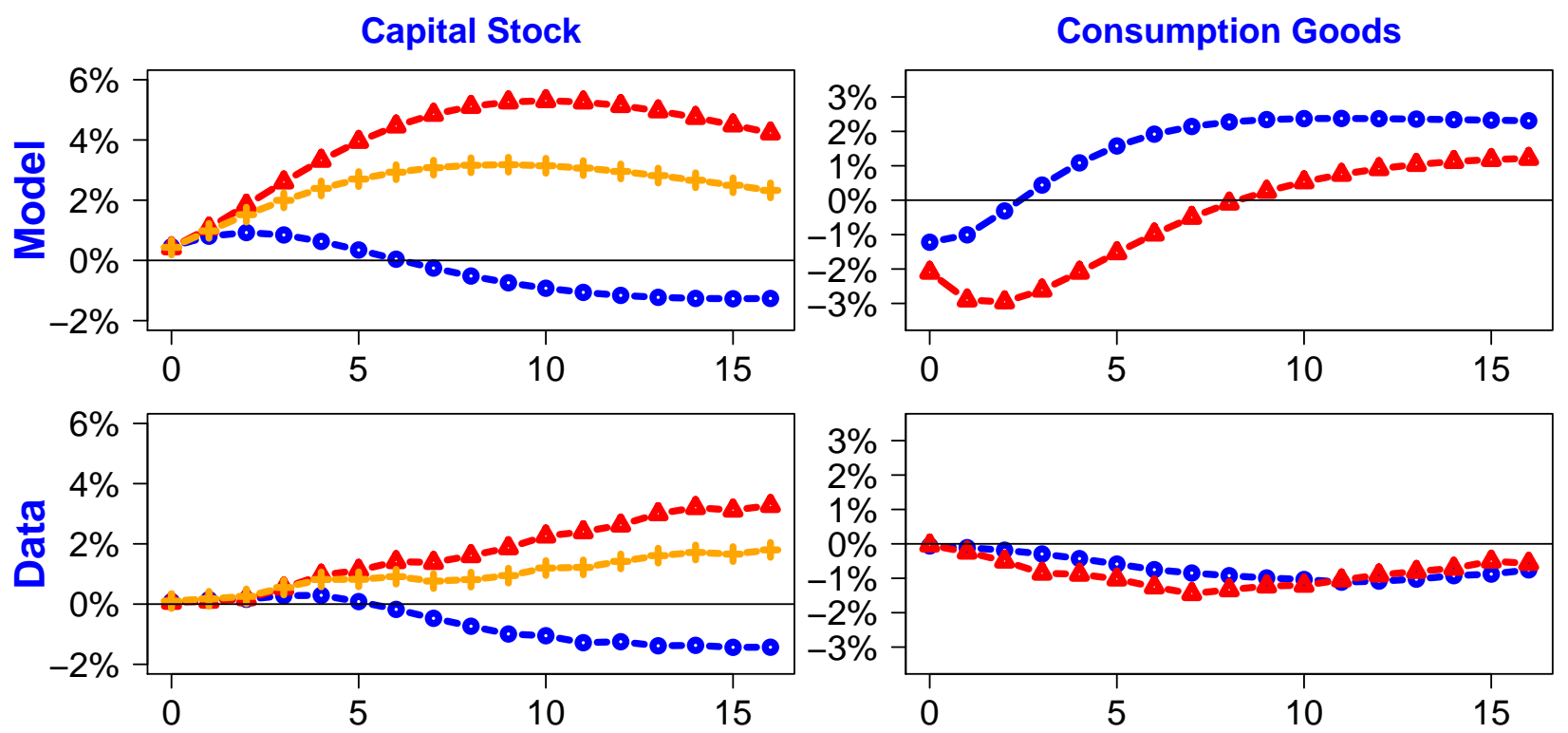

$$
\rightarrow \text { Durable } \triangle \text { Nondurable }-1 \text { Total }
$$

Figure 14: Model and Data IRFs to Contractionary MP Shock

Note: The top row shows the model responses to a 100bp contractionary monetary shock for the capital stock (left side) as well as the level of nondurable consumption and stock of consumer durable goods (right side). The bottom row shows the empirical estimates to a $100 \mathrm{bp}$ contractionary monetary policy shock. Empirical measures of consumer durables are reported as stocks while consumer nondurables are reported as expenditure flows. The capital stock estimates on the left are the same as those shown in Figure 12. The nondurable consumption series comes from the BEA's real personal consumption expenditure data. The data for the stock of consumer durable goods come from the BEA's real fixed asset accounts and do not include housing. 
As described in the previous section, the key mechanism in this model is the same as the one pointed out in Barsky et al. (2007). The driving force is that agents are extremely forward-looking; periods of lower demand are great time to buy durable goods because these goods are cheap and will provide service flows for a long time. Simple models with multiple sectors generate counterfactual predictions in response to monetary shocks, which has been termed the "comovement puzzle" and resulted in a literature attempting to generate more empirically accurate responses. In this section I compare the baseline model to several existing alternatives which attempt to fix the comovement puzzle. By attempting to offset this forward-looking behavior, these models are unable to generate the countercyclical investment patterns seen in the data.

One straightforward way to generate comovement between durable and nondurable consumption is to simply change the utility function to allow for stronger nonseparability between durable and nondurable consumption than in the baseline model. This is the approach used by Kim and Katayama (2013). While their model allows for variable capital utilization, the stock itself is fixed, and hence the model is not suitable for analyzing investment decisions. Another way of fixing the puzzle is by generating "synthetic" price stickiness. If durable goods producers are able to fully adjust their prices each period, their optimality conditions imply that price will be a constant markup over marginal cost. If the marginal costs of durable producers are not perfectly flexible, the adjustment of prices in response to monetary shocks will be limited. Carlstrom and Fuerst (2010) generate this marginal cost stickiness by introducing sticky wages to their model, but they do not have capital. Bouakez et al. (2009) use an input-output structure so that the sticky-priced nondurable good is an input into the flexibly priced durable good; while their model includes capital, it is in fixed supply.

Financial constraints offer a third approach. This strand of the literature started with Monacelli (2009) and Sterk (2010), who are able to generate comovement in both durable and nondurable consumption but do not include capital. A more recent example of this approach is Chen and Liao (2014), whose model allows for endogenous production of capital goods and serves as a starting point for my own. While it correctly predicts that total capital increases following a monetary shock, this increase is driven entirely by the durable goods sector.

Figure 15 compares the baseline model responses (in the top-left panel) to some of these alternate approaches. The second and third panels in the top row show, respectively, the responses under the assumptions of perfectly flexible prices in both sectors and the responses under the assumption of no adjustment frictions (sticky wages, habit formation, Taylor Rule persistence, and investment adjustment costs). While these two alternative setups are unable to match both the timing and persistence of the capital stocks for each sector relative to the baseline model, 
they are still able to get the direction right.
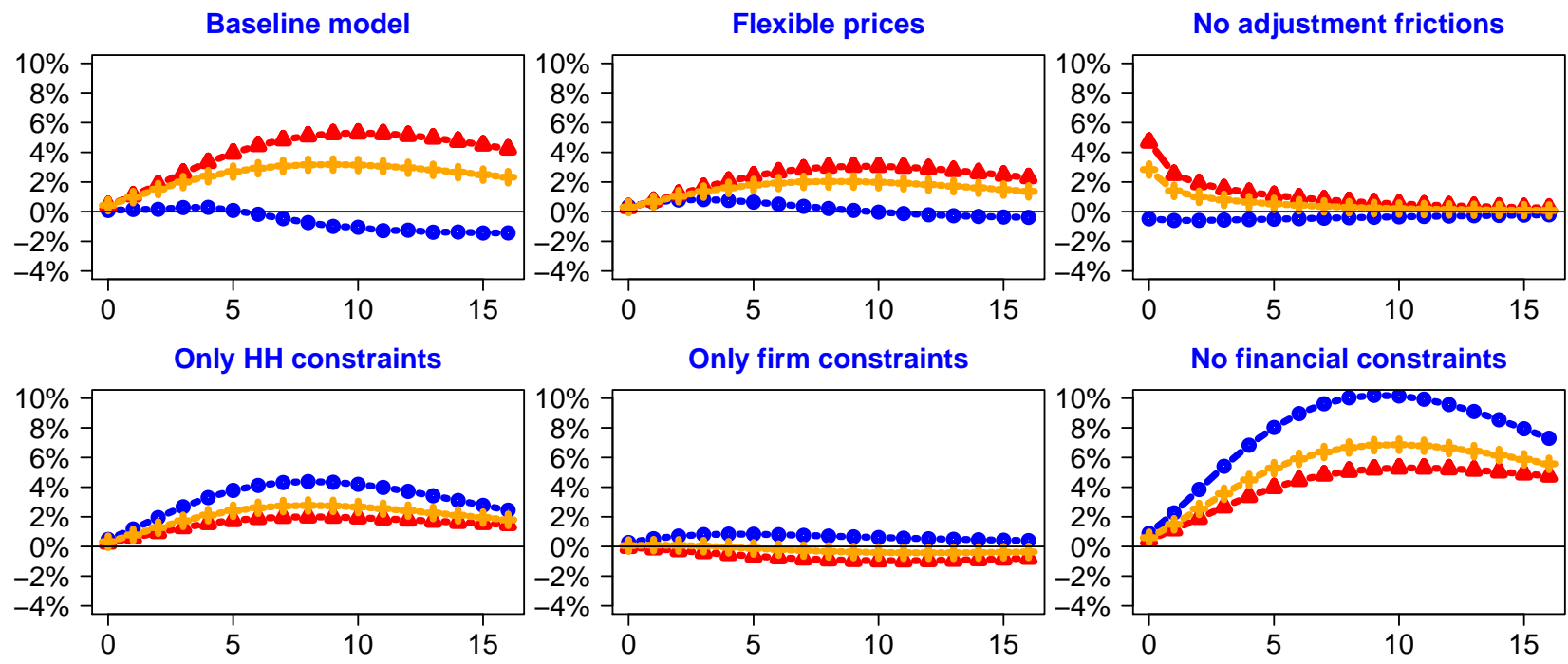

Only firm constraints
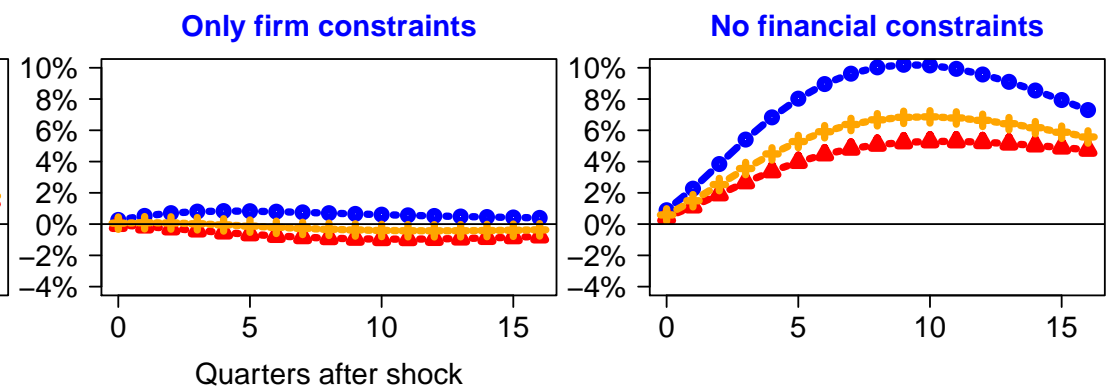

$\rightarrow$ Durable $\triangle$ Nondurable + Total

Figure 15: Capital Stock Responses under Alternate Model Assumptions

Note: All responses shown are for the capital stock to a 100bp contractionary monetary shock. The baseline model (top left) shows the same responses as in Figures 12 and 14. The flexible price responses (top middle) use the same structure as the baseline model but with no price stickiness in either sector $\left(\phi_{D}=\phi_{N}=0\right)$. The model without adjustment frictions (top right) is the same as the baseline model (including price frictions) but does not have adjustment costs on investment, wage stickiness, persistence in the Taylor Rule, or habit formation. All responses from the top row are based on models with financial frictions on both firms and households. The responses in the bottom left are from a modification of the baseline model that includes financial frictions on households but has no financial frictions for firms. The model in the bottom middle has financial frictions that apply to firms but none that apply to households. The model in the bottom right includes no financial constraints for either firms or households. All model responses shown on the bottom row include the baseline parameter values for price stickiness and adjustment costs.

For comparison, the second row shows the responses of the capital stocks in the model under different financial frictions. The bottom-left panel shows the model specification in which only households are constrained and both types of producers are unconstrained (this corresponds to the model of Chen and Liao (2014)). While this model is able to generate an increase the aggregate capital stock, it is the result of a drastically different sectoral composition; in the absence of financial constraints, the capital stock of durable producers rises significantly while declining slightly for nondurable producers, which is the opposite of what happens in the aggregate data.

The middle panel on the bottom row shows the responses under the assumption that durable producers are financially constrained but households are unconstrained. In this setup, the capital stock of durable producers increases while it falls for nondurable producers. This occurs because consumer demand for durables increases drastically in response to contractionary monetary shocks due to the drop in durable good prices, in line with the intuition of Barsky et al. 
(2007). This consumer-driven shift in demand from the nondurable to the durable sector allows durable producers to increase their capital expenditure. Finally, the lower-right panel shows the results if neither households nor firms are financially constrained. While the models without financial constraints on firms cannot match the aggregate data across sectors, they align well with the Compustat results. To the extent that more and smaller firms are able to obtain access to funding through reductions in barriers to financing over time, this suggests that the responses of constrained sectors should look more like that of the manufacturing sector in the future.

\section{Conclusion}

Understanding which types of firms are financially constrained and how this affects aggregate dynamics is a crucial research question in macroeconomics and corporate finance. I use a novel data set to show evidence that the capital stock in the manufacturing sector responds countercyclically conditional on monetary shocks. This behavior is driven by firms that display fewer symptoms of financial constraint including nondurable, large, and publicly traded firms.

Detailed building permit data from Dodge Analytics show that while the number of new permits for manufacturing structures declines in response to a contractionary monetary policy shock, the average project size increases. I provide some suggestive evidence that this can be explained by falling construction costs, which are driven by the strongly procyclical behavior of the residential construction sector. Analyzing the responses to a more general empirical estimate of the user cost of capital for the manufacturing sector shows that it falls between 0.6-0.8\% in response to a monetary shock. This implies a user cost elasticity of between -2 and -3 , a number which is modestly larger than past estimates.

A model in which durable producers and impatient consumers face financial constraints can match the data well. In response to a contractionary monetary policy shock, the relative price of durables falls and the unconstrained agents (nondurable producers and patient consumers) increase their durable purchases. In addition to fixing the comovement puzzle by generating declines in both types of consumption in response to contractionary monetary shocks, a model with financial constraints is also able to qualitatively match the responses of investment; most existing models which fix the puzzle either abstract from endogenous capital production or have predictions for the responses of investment that are at odds with the data. This model suggests that the firms which respond most to monetary policy are actually the least financially constrained. Removing financial constraints on all sectors in the model leads to investment dynamics that are even more strongly procyclical than the baseline. 
These findings have two important implications for policymakers. The first is that monetary policy can have a larger impact on the investment of unconstrained producers than constrained producers even when the latter have much more volatile and interest-sensitive demand. The second is that investment should become more countercyclical over time as financial modernization reduces the number of firms which are financially constrained.

\section{References}

Almeida, Heitor and Murillo Campello, "Financial constraints and investment-cash flow sensitivities: New research directions," 2001.

_ and _ "Financial constraints, asset tangibility, and corporate investment," The Review of Financial Studies, 2007, 20 (5), 1429-1460.

Banerjee, Shantanu, Sudipto Dasgupta, and Yungsan Kim, "Buyer-supplier relationships and the stakeholder theory of capital structure," the Journal of finance, 2008, 63 (5), 2507-2552.

Barclay, Michael J and Clifford W Smith, "The maturity structure of corporate debt," the Journal of Finance, 1995, 50 (2), 609-631.

Barsky, Robert B, Christopher L House, and Miles S Kimball, "Sticky-price Models and Durable Goods," American Economic Review, 2007, 97 (3), 984-998.

Bernanke, Ben S, Mark Gertler, and Simon Gilchrist, "The financial accelerator in a quantitative business cycle framework," Handbook of macroeconomics, 1999, 1, 1341-1393.

Blanchard, Olivier and Jordi Galí, "Real wage rigidities and the New Keynesian model," Journal of money, credit and banking, 2007, 39, 35-65.

Bouakez, Hafedh, Emanuela Cardia, and Francisco J Ruge-Murcia, "The transmission of monetary policy in a multisector economy," International Economic Review, 2009, 50 (4), $1243-1266$.

Buera, Francisco J, Joseph P Kaboski, and Yongseok Shin, "Finance and development: A tale of two sectors," American Economic Review, 2011, 101 (5), 1964-2002.

Caballero, Ricardo J, Eduardo MRA Engel, John C Haltiwanger, Michael Woodford, and Robert E Hall, "Plant-level adjustment and aggregate investment dynamics," Brookings papers on economic activity, 1995, pp. 1-54. 
Carlstrom, Charles T and Timothy S Fuerst, "Nominal rigidities, residential investment, and adjustment costs," Macroeconomic Dynamics, 2010, 14 (1), 136-148.

Chen, Been-Lon and Shian-Yu Liao, "Capital, Credit Constraints and the Comovement Between Consumer Durables and Nondurables," Journal of Economic Dynamics and Control, 2014, 39, 127-139.

Chiesa, Gabriella, "Debt and warrants: Agency problems and mechanism design," Journal of Financial Intermediation, 1992, 2 (3), 237-254.

Chirinko, Robert S, Steven M Fazzari, and Andrew P Meyer, "How responsive is business capital formation to its user cost?: An exploration with micro data," Journal of public economics, 1999, 74 (1), 53-80.

Christiano, Lawrence J, Martin Eichenbaum, and Charles L Evans, "Nominal rigidities and the dynamic effects of a shock to monetary policy," Journal of political Economy, 2005, $113(1), 1-45$.

Coibion, Olivier, "Are the Effects of Monetary Policy Shocks Big or Small?," American Economic Journal: Macroeconomics, April 2012, 4 (2), 1-32.

Crouzet, Nicolas, "Aggregate Implications of Corporate Debt Choices," The Review of Economic Studies, 2015.

_ and Neil R. Mehrotra, "Small and Large Firms Over the Business Cycle," Working Paper September 2018.

Dwenger, Nadja, "User cost elasticity of capital revisited," Economica, 2014, 81 (321), 161-186.

Erceg, Christopher and Andrew Levin, "Optimal monetary policy with durable consumption goods," Journal of Monetary Economics, 2006, 53 (7), 1341-1359.

Farre-Mensa, Joan and Alexander Ljungqvist, "Do measures of financial constraints measure financial constraints?," The Review of Financial Studies, 2016, 29 (2), 271-308.

Fazzari, Steven M, R Glenn Hubbard, Bruce C Petersen, Alan S Blinder, and James M Poterba, "Financing Constraints and Corporate Investment," Brookings papers on economic activity, 1988, 1988 (1), 141-206. 
Fuhrer, Jeffrey C, "Habit formation in consumption and its implications for monetary-policy models," American Economic Review, 2000, 90 (3), 367-390.

Gertler, Mark and Simon Gilchrist, "Monetary Policy, Business Cycles, and the Behavior of Small Manufacturing Firms," The Quarterly Journal of Economics, 1994, 109 (2), 309-340.

Giroud, Xavier and Holger M Mueller, "Firm Leverage and Unemployment During the Great Recession," Technical Report, National Bureau of Economic Research 2015.

Gomes, Joao F, Leonid Kogan, and Motohiro Yogo, "Durability of output and expected stock returns," Journal of Political Economy, 2009, 117 (5), 941-986.

Guedes, Jose and Tim Opler, "The determinants of the maturity of corporate debt issues," the Journal of Finance, 1996, 51 (5), 1809-1833.

Hadlock, Charles J and Joshua R Pierce, "New evidence on measuring financial constraints: Moving beyond the KZ index," The Review of Financial Studies, 2010, 23 (5), 1909-1940.

Hall, Robert E and Dale W Jorgenson, "Tax Policy and Investment Behavior," The American Economic Review, 1967, 57 (3), 391-414.

Hassett, Kevin A and R Glenn Hubbard, "Tax policy and business investment," in "Handbook of public economics," Vol. 3, Elsevier, 2002, pp. 1293-1343.

Holmstrom, Bengt and Jean Tirole, "Financial Intermediation, Loanable Funds, and the Real Sector," Quarterly Journal of Economics, August 1997, 112 (3), 663-691.

Innes, Robert D, "Limited liability and incentive contracting with ex-ante action choices," Journal of economic theory, 1990, 52 (1), 45-67.

Jeenas, Priit, "Monetary Policy Shocks, Financial Structure, and Firm Activity: A Panel Approach," Job Market Paper 2018.

Jordà, Òscar, "Estimation and Inference of Impulse Responses by Local Projections," American Economic Review, March 2005, 95 (1), 161-182.

Kaplan, Steven N and Luigi Zingales, "Do Investment-Cash Flow Sensitivities Provide Useful Measures of Financing Constraints?," The quarterly journal of economics, 1997, 112 (1), 169-215. 
Kim, Kwang Hwan and Munechika Katayama, "Non-separability and sectoral comovement in a sticky price model," Journal of Economic Dynamics and Control, 2013, 37 (9), 1715-1735.

Kiyotaki, Nobuhiro and John Moore, "Credit cycles," Journal of political economy, 1997, $105(2), 211-248$.

Kudlyak, Marianna and Juan M Sánchez, "Revisiting the Behavior of Small and Large Firms During the 2008 Financial Crisis," Journal of Economic Dynamics and Control, 2017, 77, 48-69.

Kuttner, Kenneth N, "Monetary policy surprises and interest rates: Evidence from the Fed funds futures market," Journal of monetary economics, 2001, 47 (3), 523-544.

Monacelli, Tommaso, "New Keynesian models, durable goods, and collateral constraints," Journal of Monetary Economics, 2009, 56 (2), 242-254.

Nakamura, Emi and Jón Steinsson, "High frequency identification of monetary nonneutrality: The information effect," Quarterly Journal of Economics, 2018.

Ottonello, Pablo and Thomas Winberry, "Financial Heterogeneity and the Investment Channel of Monetary Policy," Working Paper, National Bureau of Economic Research 2018.

Rajan, Raghuram G and Luigi Zingales, "Financial dependence and growth," Technical Report, National bureau of economic research 1996.

Romer, Christina D. and David H. Romer, "A New Measure of Monetary Shocks: Derivation and Implications," American Economic Review, September 2004, 94 (4), 713-727.

Sterk, Vincent, "Credit frictions and the comovement between durable and non-durable consumption," Journal of Monetary Economics, 2010, 57 (2), 217-225.

Tirole, Jean, The theory of corporate finance, Princeton University Press, 2010.

Whited, Toni M and Guojun Wu, "Financial constraints risk," The Review of Financial Studies, 2006, 19 (2), 531-559. 


\section{A Detailed Data Description}

\section{A.1 QFR Data}

The aggregate data come from the Quarterly Financial Report for Manufacturing Corporations (QFR). This survey dates back to World War II, when it was administered by the Office of Price Administration. The Census Bureau has been responsible for administering the survey since 1982. These data series are used as input to macroeconomic aggregates such as corporate profits and the US financial accounts. The QFR sample, which includes approximately 10,000 firms in a given quarter, is chosen based on asset sizes reported in corporate tax returns; any firm with more than $\$ 250,000$ in domestic assets is eligible for inclusion, and any firm with more than $\$ 250$ million is included in the sample with certainty. Firms who reside between these thresholds are chosen randomly with the goal of obtaining a representative sample and are included for 8 consecutive quarters with one-eighth of the sample replaced each quarter.

Data from 1987Q4 and beyond are available for download from the Census Bureau's website. ${ }^{9}$ Publicly available data from before that time, however, can only be found in physical publications or microfilm. Using these physical copies, I have digitized the data going back to 1966Q1. This process consisted of mostly manual entry and occasional use of optical character recognition (OCR) software when available. To ensure that the data series were digitized correctly, I have checked that aggregating the component series by either size or sector add up to the correct total in each quarter.

Each physical publication includes observations for the current quarter as well as the four preceding quarters. With few exceptions most of the data series were digitized from the publications in Q1 of each year. Using these five level observations, I calculated the four implied quarterly growth rates, giving me a series of growth rates. By using growth rates calculated within each release, I avoid problems from comparing levels before and after methodological changes (including changes in accounting procedures in 1973 and industry reclassifications in 1984 and 2001). I then applied these growth rates to the levels of the most recent releases, effectively taking the original growth paths and shifting them to the most up-to-date level.

Beyond adjusting for revisions, I have to account for the fact that the data are not seasonally adjusted and in nominal terms. I use calendar quarter fixed effects for each regression in my default specification to address these seasonality concerns, though the results are robust to using the Census Bureau's X-13ARIMA-SEATS seasonal adjustment process or a four-quarter moving

\footnotetext{
$9_{\text {https://www . census.gov/econ/qfr/ }}$
} 
average. I deflate the stock of net property, plant, and equipment using the nonresidential fixed investment price index. Sales for each sector are deflated using the manufacturing output price deflator for that sector after linearly interpolating it to a quarterly frequency. All other variables are deflated using the GDP price index.

The respondents are aggregated by sector as well as asset size. The data consist of eight nominal asset "buckets": under $\$ 5$ million, $\$ 5-10$ million, $\$ 10-25$ million, $\$ 25-50$ million, $\$ 50-100$ million, \$100-250 million, \$250-1,000 million, and $\$ 1+$ billion. One issue with using the size data is that the cutoffs are in nominal values and fixed over time; a firm with $\$ 50$ million in assets in 1967 is much larger relative to the size of the total manufacturing sector than a firm with $\$ 50$ million assets in 2007. One way to address this is to combine many of the smaller bins into one "small" classification. For my baseline specification, I follow Crouzet (2015) in classifying all of the firms with less than $\$ 1$ billion in nominal assets as being "small". An alternative approach uses percentiles of sales. This is the approach used in Gertler and Gilchrist (1994) (who use a 30\% threshold) and Kudlyak and Sánchez (2017) (who use 25\%). My results are robust to calcuating the size cutoffs in this way.

Industries are classified by the Census Bureau based on sources of revenue. As part of its submission, each company in the survey reports a breakdown of gross receipts by source industry. To be in the scope of the QFR manufacturing sample, a firm must have manufacturing as its largest source of gross receipts. Once a corporation is assigned to the manufacturing sector, it is categorized into a subsector based on its largest share of manufacturing receipts. For example, if a firm has $40 \%$ of its revenue from manufacturing and $30 \%$ each from mining and retail trade, then the firm would be classified in the manufacturing sector. If $60 \%$ of the firm's manufacturing activity was conducted in the machinery subsector and $40 \%$ in the chemicals subsector, then the activities of the entire corporation would be assigned to the machinery subsector. These classifications are reviewed periodically and changed as needed for as long as the corporation remains in the sample.

To provide further evidence that the QFR data are in line with other measures of the capital stock, I can compare them to fixed asset data from the Bureau of Economic Analysis (BEA). These data provide end-of-year estimates of the value of total fixed assets for both the durable and nondurable manufacturing sectors. Figure 16 shows the year-over-year changes in the BEA measure compared to the Q4/Q4 changes in the QFR data and suggests that the two data series are capturing the same fundamental investment behavior. The correlations between the BEA and QFR measures are high for the total series (0.87) as well as both the durable (0.83) and nondurable (0.81) subseries, suggesting that the QFR data can be appropriately described as a 
higher-frequency and more detailed version of the BEA fixed asset data.
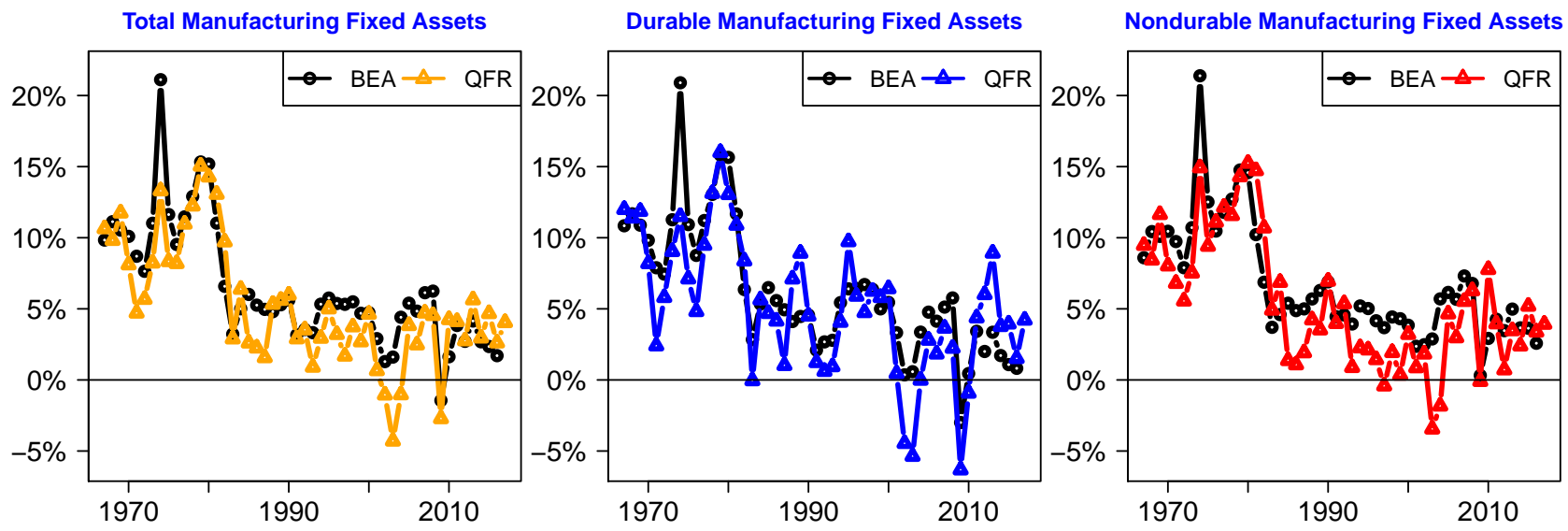

Figure 16: Y/Y \% Changes in BEA and QFR Fixed Asset Measures

Note: This figure compares the yearly percent changes in the BEA and QFR measures of the nominal fixed asset stock for the manufacturing sector. The QFR numbers are shown as the year-over-year change in the fourth quarter of each year for comparison to the BEA data (which are at an annual frequency and recorded at year-end).

\section{A.2 Compustat Data}

This section describes in detail the construction of the firm-level data used in Section 3. All of the variable definitions are quite standard and follow the literature closely, especially Jeenas (2018) and Ottonello and Winberry (2018). I use the nonresidential fixed investment price index to deflate the capital stock, the manufacturing and the GDP price index to deflate all other variables. While earliest observations in my final sample occur in 1972 the first few years of data include fewer than 100 firms in each year, so I use data starting in 1975 (which includes more than 2,000). In line with my analysis of aggregate data, I only consider monetary shocks that occur up to 2004 .

- Manufacturing: My analysis focuses on the manufacturing sector. I define a firm to be in the manufacturing sector if it is classified as being in manufacturing according to either the SIC (codes starting with 20-39) or NAICS (codes starting with 31-33). These can be classified into durable or nondurable producers according to the following sectors:

To match the definitions used in the QFR data as closely as possible, I classify firms as durable or nondurable according to the following procedure: 


\begin{tabular}{||c|c|c||}
\hline & SIC & NAICS \\
\hline Durable & $24-25,32-40$ & $33,321,327$ \\
\hline Nondurable & $20-23,26-31$ & $31,322-326$ \\
\hline
\end{tabular}

1. Firms are classified as durable producers if they have a durable NAICS code as defined above.

2. If a firm has no NAICS code but has a durable SIC code as defined above, I define it as durable.

3. In rare instances, the NAICS and SIC codes suggest different sectors; this occurs because a small number of industries have been reclassified over time. In these cases I use the NAICS classification.

- Investment: This variable denotes the capital stock of each firm at the end of the quarter. As the initial entry I use the firm's first observation of Property, Plant, and Equipment (Gross), which is item 118 and denoted PPEGTQ in the Compustat database. From this initial level, I add the quarterly change in Property, Plant, and Equipment (Net), which is item 42 and denoted PPENTQ. I use this method because there are many more observations of the net measure than the gross measure of each firm's capital stock. If a firm is missing a single value of PPENTQ between two nonmissing values, I linearly impute it using the observations on either side. For instances of two or more consecutive missing values for a firm, no imputation is done. I only consider firms with at least 40 consecutive quarterly observations after imputation in my main analysis.

- Total and net current leverage: I define leverage as the sum of current liabilities $(D L C Q$, item 45) and long-term debt ( $D L T T Q$, item 71) divided by firm size as measured total assets (ATQ, item 44). I standardize leverage by subtracting its mean and dividing by its standard deviation across the entire sample. I define net current leverage as the ratio of short-term assets minus short-term liabilities to total assets $\left(\frac{A C T Q-L C T Q}{A T Q}\right)$.

- Dividends: I use item $D V Y$ as my measure of dividends. I consider both a dummy variable for whether a firm paid dividends in a given quarter and a dividend rate, which I scale by common equity equity $(C E Q Q)$.

- Dropped observations: To minimize the effects of outliers and reporting errors, I exclude firm-quarter observations with any of the following features: 
1. A ratio of acquisitions $(A Q C Y)$ to assets $(A T Q)$ larger than $5 \%$.

2. An investment rate (defined as $\frac{k_{t}-k_{t-1}}{k_{t-1}}$ ) in the top or bottom 0.5 percent of the distribution.

3. A leverage ratio greater than 10 or a net current leverage ratio either above 10 or below -10 .

4. Changes in quarterly real sales of more than $100 \%$ or less than $-100 \%$.

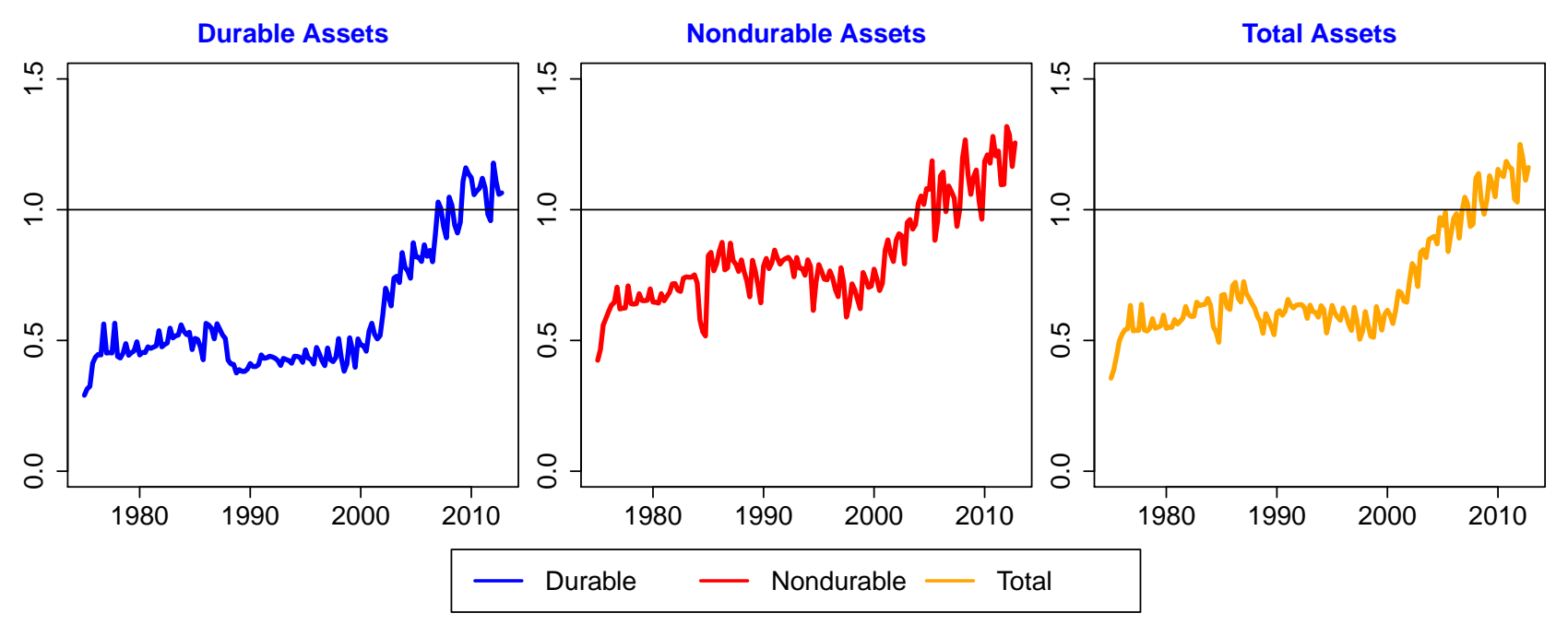

Figure 17: Ratio of Compustat to QFR Measures of Total Assets

Note: This figure shows the ratio of total assets in manufacturing firms in Compustat to total assets for all manufacturing firms from the QFR in each quarter.

One reason why the results using the Compustat data might not match those using the QFR data is because of sample selection. As a result, it is useful to compare the coverage between the two different measures. Figure 17 shows the ratios of total assets in the Compustat sample to the analogous measure in the QFR data. From 1975 until the early 2000s, this ratio was about $50 \%$ for durables and $70 \%$ for durables. Starting in 2000, however, it climbed sharply and has actually risen above 1 in recent years. This can occur because Compustat reports all of a firm's asset holdings regardless of country of residence while the QFR data only report domestic operations and suggests that the international operations of the largest US manufacturers are growing faster than the pool of small domestic producers. It can also occur due to differences in classification. While SIC codes in both Compustat and the QFR data are in principle assigned based on the distribution of revenues, these 
assignments are made by separate entities (the Census Bureau and Securities and Exchange Commission, respectively) and might not match in all cases, especially in the case of firms which produce a variety of different goods and services.

\section{B Robustness Checks}

This section discusses a variety of robustness checks on my main results. I show that the aggregate results from Section 2 and the Compustat panel regressions in Section 3 hold across a variety of starting dates and shock identification strategies. These results provide support for my main finding that aggregate investment in the manufacturing sector is countercyclical conditional on monetary shocks and that this behavior is driven by the least financially constrained firms.

\section{B.1 Aggregate Regressions}

My baseline specification uses narrative monetary shocks identified in the manner of Romer and Romer (2004) that span from 1970-2004. The starting point corresponds to the first full year for which the shocks are available (including the requirement of four lags in Equation 1). The ending year means that all outcomes after 2008 (which represents the last full year when the US economy was outside of the ZLB) are excluded. Coibion (2012) has shown that most of the largest shocks in the sample occur during the 1970s and early 1980s and that excluding these periods can meaningfully impact the estimated effects of monetary policy. The results starting in 1980 and 1990 are shown in Figures 18 and 19. I also consider shocks identified from a vector autoregression (VAR) based on Christiano et al. (2005) (Figure 20).

In terms of the aggregate responses of real sales and investment, the estimates starting in 1980 match closely the main results. ${ }^{10}$ The capital stock responses of the largest firms are quite similar across both the post-1980 and post-1990 samples. The responses of the small firms are much noisier but this due in part to the long-term decline in the importance of small firms. ${ }^{11}$ While the VAR effects are more muted, they go in the right direction and still show significant increases in the capital stock by the end of the response horizon.

\footnotetext{
${ }^{10}$ The aggregate responses will not always be convex combinations of the responses of the component series because they are estimated using separate regressions. These differences are negligible in the baseline results but become more pronounced as the sample shrinks and the coefficient estimates for the controls and intercepts become less precise.

${ }^{11}$ Manufacturers with at least $\$ 1 \mathrm{bn}$ in total assets held $48 \%$ of all manufacturing assets in 1970Q1, $62 \%$ in 1980Q1, $71 \%$ in 1990Q1, and $79 \%$ in 2000Q1.
} 

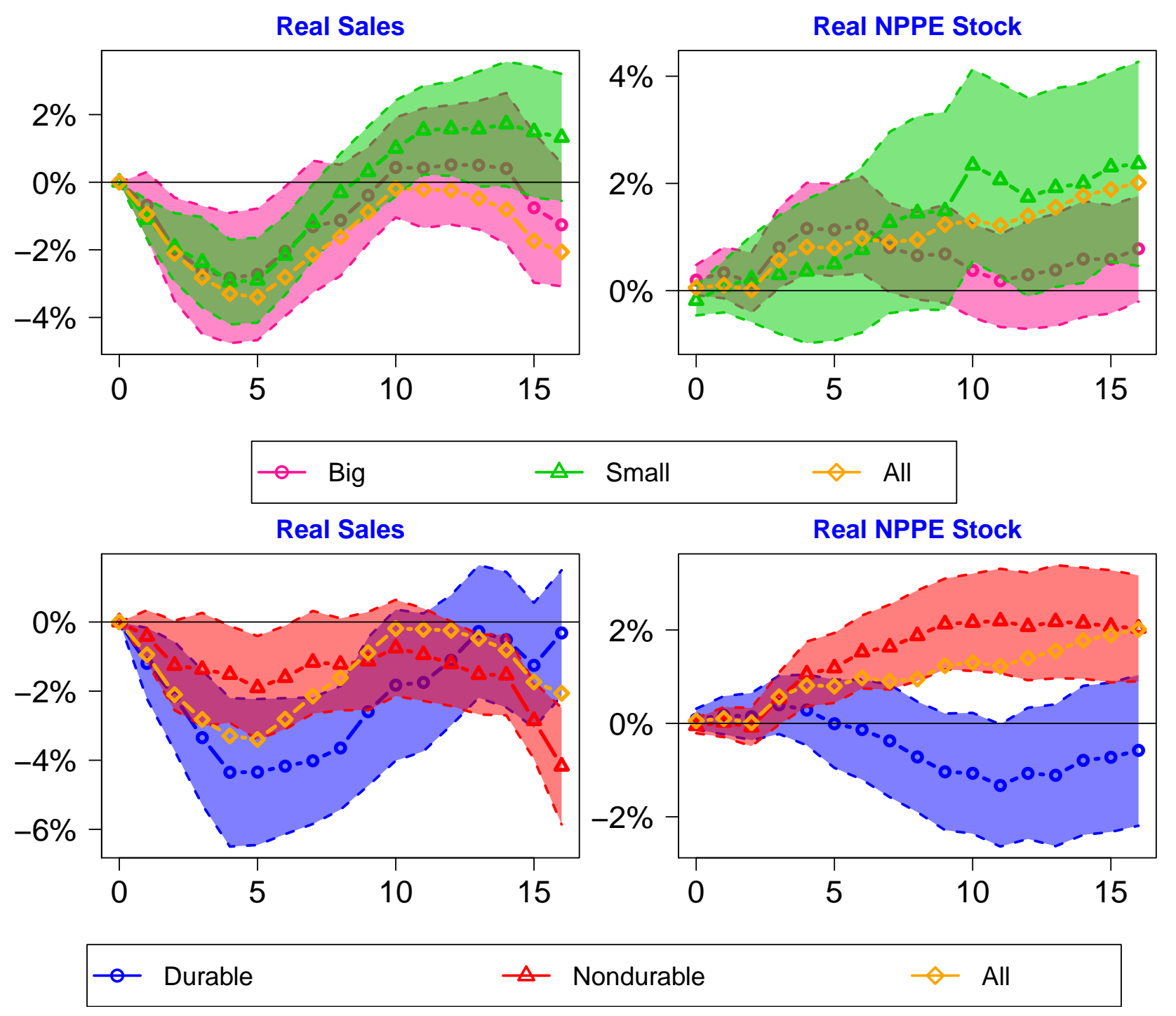

Figure 18: Responses Starting in 1980

Note: This figure shows the coefficient estimates $\gamma_{h}^{i}$ from Equation 1, which corresponds to the effects of a $100 \mathrm{bp}$ contractionary monetary shock. "Small" firms are defined as those with $<\$ 1$ bn in nominal assets and "Big" firms those with $\geq \$ 1$ bn in nominal assets. Sales are deflated using the BEA's manufacturing output deflator for each sector. NPPE stocks are deflated using the NIPA nonresidential fixed investment price index. 90\% confidence intervals are calculated using Newey-West standard errors. Regressions include shocks from 1980-2004 and outcomes through 2008. Estimated aggregate responses will not necessarily be convex combinations of the component responses because they are estimated using separate regressions. 

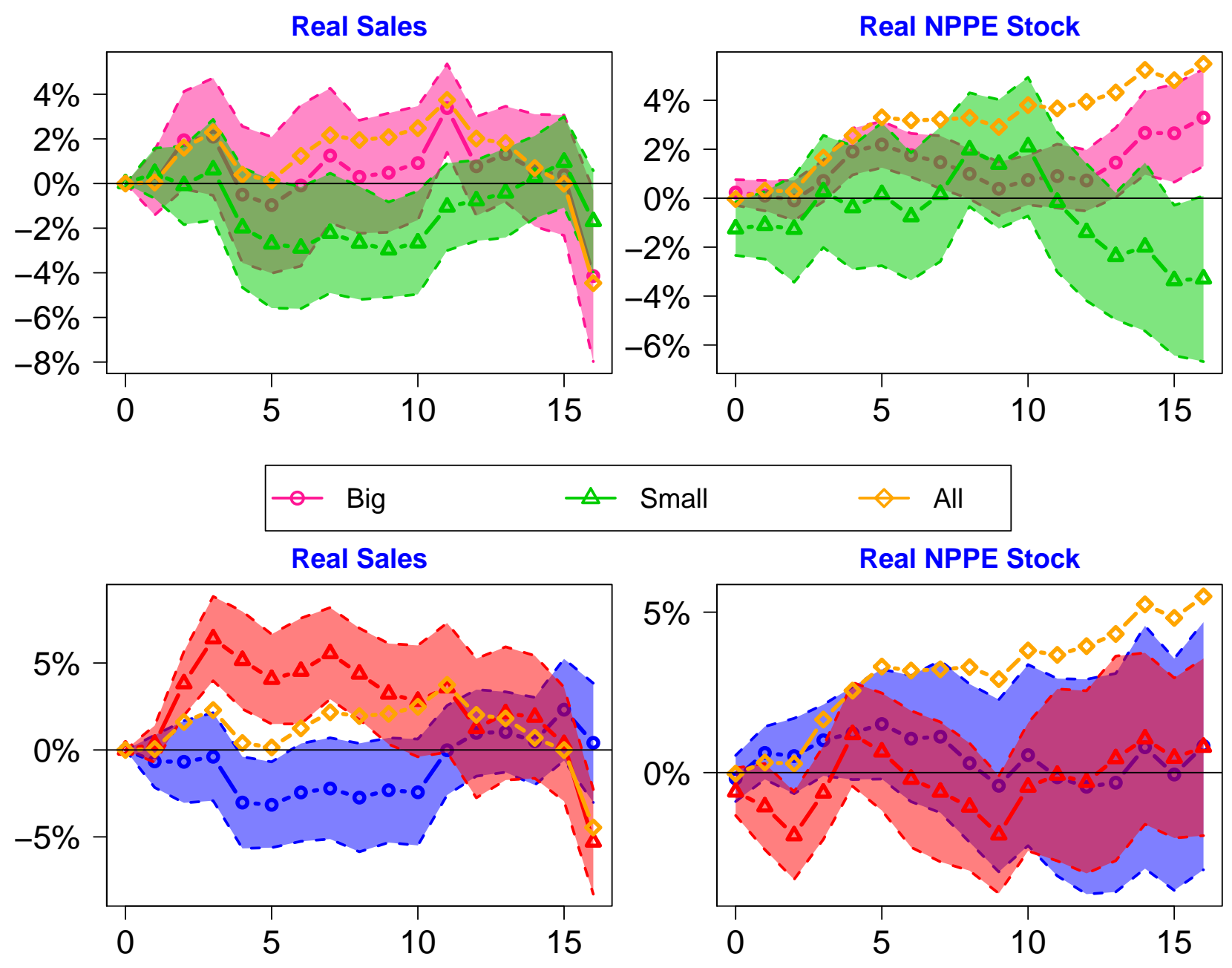

$\rightarrow-\Delta$ Nondurable $\quad \diamond$ All

Figure 19: Responses Starting in 1990

Note: This figure shows the coefficient estimates $\gamma_{h}^{i}$ from Equation 1, which corresponds to the effects of a $100 \mathrm{bp}$ contractionary monetary shock. "Small" firms are defined as those with $<\$ 1$ bn in nominal assets and "Big" firms those with $>\$ 1$ bn in nominal assets. Sales are deflated using the BEA's manufacturing output deflator for each sector. NPPE stocks are deflated using the NIPA nonresidential fixed investment price index. 90\% confidence intervals are calculated using Newey-West standard errors. Regressions include shocks from 1990-2004 and outcomes through 2008. Estimated aggregate responses will not necessarily be convex combinations of the component responses because they are estimated using separate regressions. 

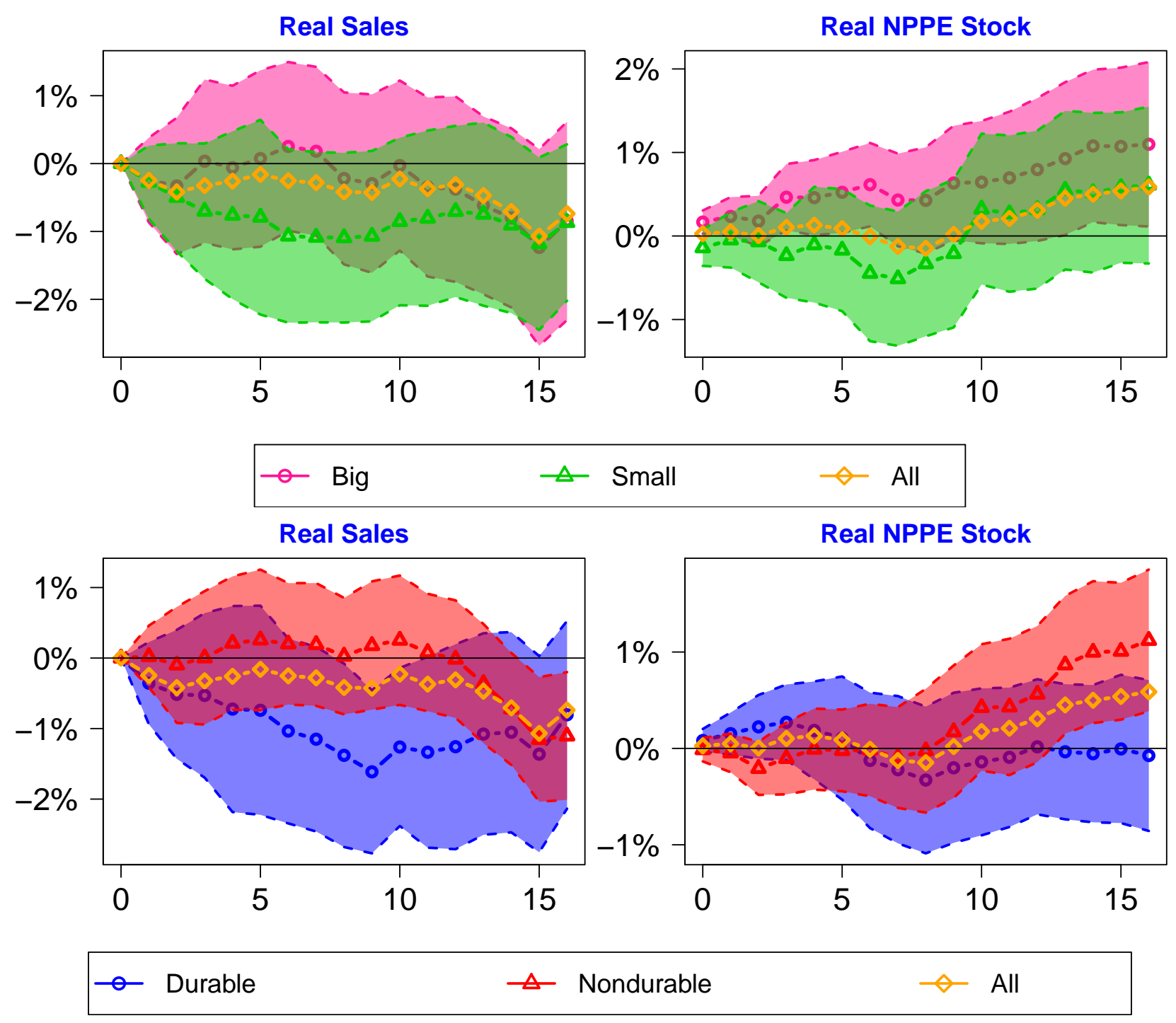

Figure 20: Responses Using VAR shocks

Note: This figure shows the coefficient estimates $\gamma_{h}^{i}$ from Equation 1, which corresponds to the effects of a 100bp contractionary monetary shock taken from a VAR. VAR shocks are estimated from a vector autoregression based on Christiano et al. (2005) that includes log industrial production, the unemployment rate, log CPI, log commodity prices, and the Federal Funds rate. The VAR is estimated using monthly data from 1966-2008 and includes 12 lags. Quarterly shocks are obtained by summing up the monthly shocks in each month of the quarter. "Small" firms are defined as those with < $\$ 1$ bn in nominal assets and "Big" firms those with $\geq \$ 1 \mathrm{bn}$ in nominal assets. Sales are deflated using the BEA's manufacturing output deflator for each sector. NPPE stocks are deflated using the NIPA nonresidential fixed investment price index. 90\% confidence intervals are calculated using Newey-West standard errors. Regressions include shocks from 1970-2004 and outcomes through 2008. Estimated aggregate responses will not necessarily be convex combinations of the component responses because they are estimated using separate regressions. 


\section{B.2 Panel Regressions}

The previous subsection considered a variety of robustness checks for my aggregate specification, which used QFR data. This subsection considers a similar set of checks on the results from Section 3 including several measures of high-frequency monetary shocks that cover a variety of time periods and encompass several distinct identification strategies.

I consider specifications using shocks identified from a vector autoregression (VAR) as well as estimates of high-frequency shocks from Kuttner (2001) and Nakamura and Steinsson (2018). Due to data availability, the shocks do not all use the same time horizon. The first three panels, including the baseline R\&R approach, all start in 1975. The N\&S shocks start in 1995, and the Kuttner shocks start in 1990. While the coefficient estimates are not always significant, they are almost always positive despite using different time horizons and identification strategies. These estimates are shown in the top panels of Figure 21. For comparison, all of the results are combined in the bottom panel.

This paper's main finding is that the capital stock of the manufacturing firms increases in response to contractionary monetary policy shocks and that financial factors can explain why some firms increase their investment while others do not. Taken together, the robustness checks in this section indicate that my results are not driven by the sample period, data source, or shock identification strategy. 


\section{Average NPPE Stock Response for Compustat Manufacturing Firms}
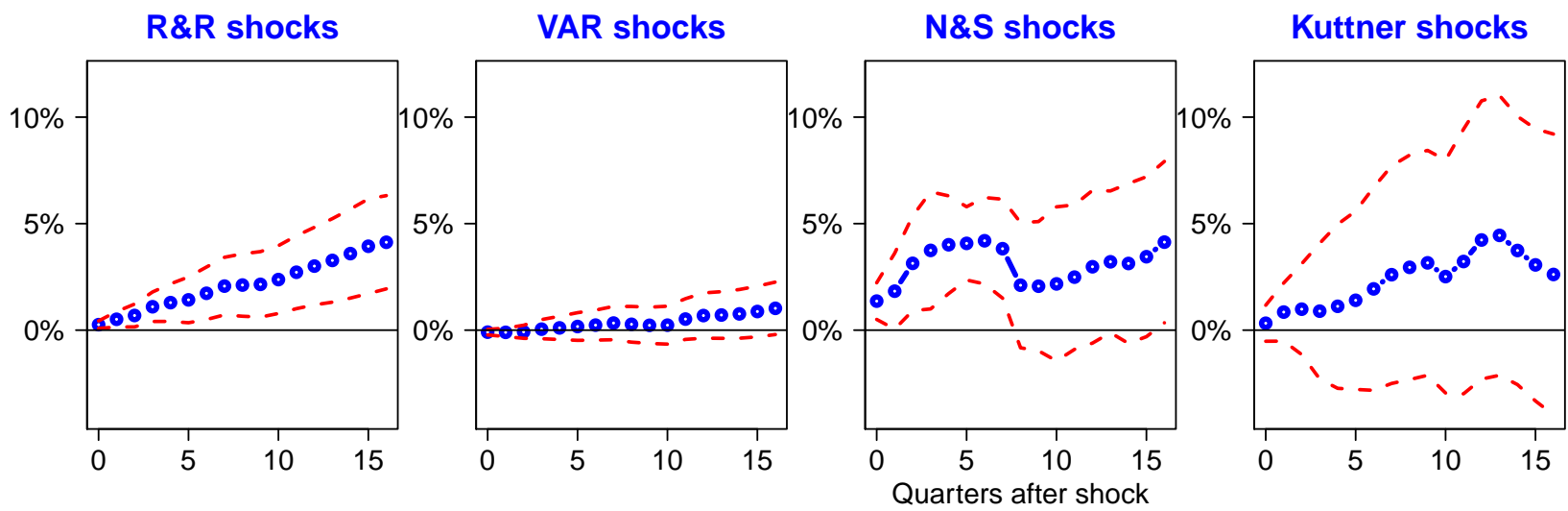

Coefficient Estimate - - +/-1.65 SE

\section{Average NPPE Stock Response for Compustat Manufacturing Firms}

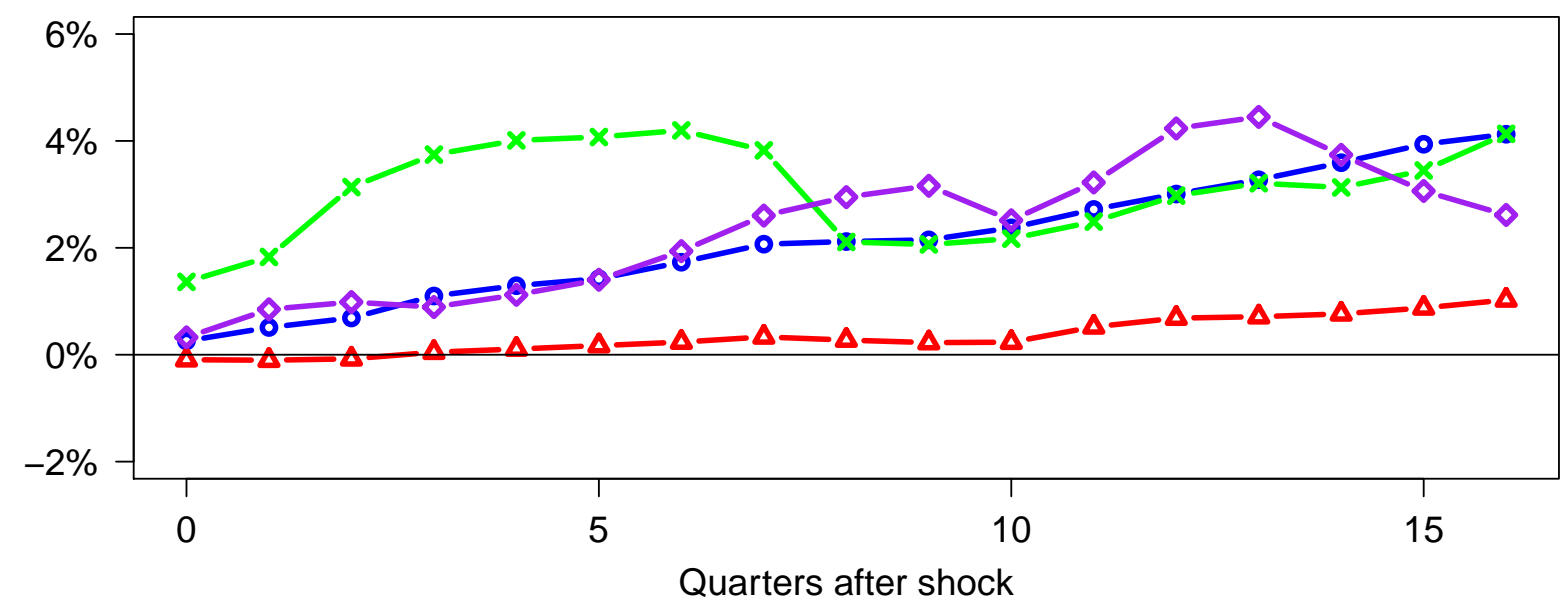

$\rightarrow$ R\&R shocks $\triangle$ VAR shocks $\rightarrow$ N\&S shocks $\rightarrow$ Kuttner shocks

Figure 21: Empirical Responses to 100bp Contractionary MP Shock

Note: These impulse responses are estimated from Equation 3. All controls are the same in all specifications. The blue line uses narrative shocks calculated in the spirit of Romer and Romer and include shocks from 1975-2004 and outcomes through 2008. VAR shocks are estimated from a vector autoregression based on Christiano et al. (2005) that includes log industrial production, the unemployment rate, log CPI, log commodity prices, and the Federal Funds Rate. The VAR is estimated using monthly data and includes 12 lags. Quarterly shocks are obtained by summing up the monthly shocks in each month of the quarter from 1975-2004 and outcomes are estimated through 2008. The N\&S shock series comes from Nakamura and Steinsson (2018); I use their Federal Funds Rate shock (which excludes the estimated information content of each release) and estimate my results using shocks from 1995-2004 and outcomes through 2008. The Kuttner shocks come from Kuttner (2001) and include shocks from 1990-2004 and outcomes through 2008. $90 \%$ confidence intervals are calculated using Driscoll-Kraay standard errors. 


\section{Full Set of Equilibrium Conditions}

This section shows the set of equations which fully characterize the solution to the model presented in Section 4. After plugging in the household's demand curve, the full Lagrangian can be formulated as below. $\xi^{N}$ is set sufficiently high such that the borrowing constraint does not bind for nondurable producers and thus $\mu_{t}^{N}=0$; as a result, the sector-specific superscripts are omitted in the body of the paper.

$$
\begin{array}{r}
\mathcal{L}=E_{0} \sum_{t=0}^{\infty} \beta_{S}^{t} \frac{\lambda_{S, t}}{\lambda_{S, 0}}\left\{p_{t}^{j}(i)\left(\frac{p_{t}^{j}(i)}{P_{t}^{j}}\right)^{-\epsilon^{j}} Y_{t}^{j}-w_{t} N_{t}^{j}-p_{t}^{D} I_{t}^{j}-\frac{\phi^{j}}{2}\left(\Pi_{t}^{j}(i)-1\right)^{2} Y_{t}^{j}(i)\right. \\
+m k_{t}^{j}\left[I_{t}^{j}\left(1-\frac{\theta_{j}}{2}\left(\frac{I_{j, t}}{I_{j, t-1}}-1\right)^{2}\right)+\left(1-\delta^{j}\right) K_{t}^{j}-K_{t+1}^{j}\right]+\mu_{t}^{j}\left[\xi^{j} p_{t}^{D} K_{t}^{j}-w_{t} N_{t}^{j}-p_{t}^{D} I_{t}^{j}\right] \\
\left.+m c_{t}^{j}\left[A_{t}\left(K_{t}^{j}\right)^{\alpha^{j}}\left(N_{t}^{j}\right)^{1-\alpha^{j}}-Y_{t}^{j}(i)\right]\right\}
\end{array}
$$

The full set of equilibrium conditions are as follows:

$$
\begin{gathered}
\eta\left(\frac{1}{C_{B, t}^{N}-h C_{B, t-1}^{N}}-h \beta_{B} E_{t}\left[\frac{1}{C_{B, t+1}^{N}-h C_{B, t}^{N}}\right]\right)=\lambda_{B, t} p_{t}^{N} \\
w_{t}=\left(\frac{\nu_{B} H_{i, t}^{\chi}}{\lambda_{B, t}}\left(1+\mu^{w}\right)\right)^{1-\rho_{w}}\left(\frac{w_{t-1}}{\Pi_{t}}\right)^{\rho_{w}} \\
\lambda_{B, t} p_{t}^{D}=\frac{(1-\eta)}{D_{B, t}}+m \psi_{t} p_{t}^{D} \lambda_{B, t}+\beta_{B} E_{t}\left[\lambda_{B, t+1} p_{t+1}^{D}\left(1-\delta^{D}\right)\right] \\
\left(1+i_{t}\right) \psi_{t}=1-\beta_{B} E_{t}\left[\frac{\lambda_{B, t+1}\left(1+i_{t}\right)}{\lambda_{B, t} \Pi_{t+1}}\right] \\
D_{B, t}=C_{B, t}^{D}+\left(1-\delta^{D}\right) D_{B, t-1} \\
\left(1+i_{t}\right) B_{B, t}=m p_{t}^{D} D_{B, t} \\
p_{t}^{N} C_{B, t}^{N}+p_{t}^{D} C_{B, t}^{D}+\frac{\left(1+i_{t-1}\right) B_{B, t-1}}{\Pi_{t}}=B_{B, t}+w_{t}^{D} H_{B, t}^{D}+w_{t}^{N} H_{B, t}^{N} \\
\eta\left(\frac{1}{C_{S, t}^{N}-h C_{S, t-1}^{N}}-h \beta_{S} E_{t}\left[\frac{1}{C_{S, t+1}^{N}-h C_{S, t}^{N}}\right]\right)=\lambda_{S, t} p_{t}^{N}
\end{gathered}
$$




$$
\begin{aligned}
& w_{t}=\left(\frac{\nu_{S} H_{S, t}^{\chi}}{\lambda_{S, t}}\left(1+\mu^{w}\right)\right)^{1-\rho_{w}}\left(\frac{w_{t-1}}{\Pi_{t}}\right)^{\rho_{w}} \\
& \lambda_{S, t} p_{t}^{D}=\frac{(1-\eta)}{D_{S, t}}+\beta_{S} E_{t}\left[\lambda_{S, t+1} p_{t+1}^{D}\left(1-\delta_{D}\right)\right] \\
& D_{S, t}=C_{S, t}^{D}+\left(1-\delta^{D}\right) D_{S, t-1} \\
& \lambda_{S, t}=\beta_{S} E_{t}\left[\frac{\lambda_{S, t+1}\left(1+i_{t}\right)}{\Pi_{t+1}}\right] \\
& w_{t}\left(1+\mu_{t}\right)=\left(1-\alpha^{D}\right) m c_{t}^{D} A_{t}\left(K_{t}^{D}\right)^{\alpha^{D}}\left(H_{t}^{D}\right)^{-\alpha^{D}} \\
& w_{t}=\left(1-\alpha^{N}\right) m c_{t}^{N} A_{t}\left(K_{t}^{N}\right)^{\alpha^{N}}\left(H_{t}^{N}\right)^{-\alpha^{N}} \\
& \left(1+\mu_{t}\right) p_{t}^{D}=m k_{D, t}\left[1-\frac{\theta_{D}}{2}\left(\frac{I_{D, t}}{I_{D, t-1}}-1\right)^{2}-\theta_{D}\left(\frac{I_{D, t}}{I_{D, t-1}}-1\right)\left(\frac{I_{D, t}}{I_{D, t-1}}\right)\right] \\
& +\beta_{S} E_{t}\left[m k_{t+1}^{D} \theta_{D}\left(\frac{I_{D, t+1}}{I_{D, t}}-1\right)\left(\frac{I_{D, t+1}}{I_{D, t}}\right)\right] \\
& p_{t}^{D}=m k_{N, t}\left[1-\frac{\theta_{N}}{2}\left(\frac{I_{N, t}}{I_{N, t-1}}-1\right)^{2}-\theta_{N}\left(\frac{I_{N, t}}{I_{N, t-1}}-1\right)\left(\frac{I_{N, t}}{I_{N, t-1}}\right)\right] \\
& +\beta_{S} E_{t}\left[m k_{t+1}^{N} \theta_{N}\left(\frac{I_{N, t+1}}{I_{N, t}}-1\right)\left(\frac{I_{N, t+1}}{I_{N, t}}\right)\right] \\
& m k_{D, t}=\beta_{S} E_{t}\left[\left(\frac{\lambda_{S, t+1}}{\lambda_{S}}\right)\left(A_{t+1} \alpha_{N} K_{D, t+1}^{\alpha_{D}-1} N_{D, t+1}^{1-\alpha_{D}} m c_{t+1}^{D}+m k_{D, t+1}\left(1-\delta_{K}\right)\right)+\xi p_{t+1}^{D} \mu_{t+1}\right] \\
& m k_{N, t}=\beta_{S} E_{t}\left[\left(\frac{\lambda_{S, t+1}}{\lambda_{S}}\right)\left(A_{t+1} \alpha_{N} K_{N, t+1}^{\alpha_{N}-1} N_{N, t+1}^{1-\alpha_{N}} m c_{t+1}^{N}+m k_{N, t+1}\left(1-\delta_{K}\right)\right)\right] \\
& w_{t} H_{t}^{D}+p_{t}^{D} I_{t}^{D}=\xi p_{t}^{D} K_{t}^{D} \\
& {\left[\left(1-\epsilon^{D}\right) p_{t}^{D}+\epsilon^{D} m c_{t}^{D}\right]-\phi^{D}\left(\Pi_{t}^{D}-1\right) \Pi_{t}^{D}+\beta_{S} \phi^{D} E_{t}\left[\left(\frac{\lambda_{S, t+1}}{\lambda_{S, t}}\right)\left(\Pi_{t+1}^{D}-1\right) \Pi_{t+1}^{D}\left(\frac{Y_{t+1}^{D}}{Y_{t}^{D}}\right)\right]=0} \\
& {\left[\left(1-\epsilon^{N}\right) p_{t}^{N}+\epsilon^{N} m c_{t}^{N}\right]-\phi^{N}\left(\Pi_{t}^{N}-1\right) \Pi_{t}^{N}+\beta_{S} \phi^{N} E_{t}\left[\left(\frac{\lambda_{S, t+1}}{\lambda_{S, t}}\right)\left(\Pi_{t+1}^{N}-1\right) \Pi_{t+1}^{N}\left(\frac{Y_{t+1}^{N}}{Y_{t}^{N}}\right)\right]=0}
\end{aligned}
$$




$$
\begin{aligned}
& Y_{t}^{D}=A_{t}\left(K_{t}^{D}\right)^{\alpha^{D}}\left(H_{t}^{D}\right)^{1-\alpha^{D}} \\
& Y_{t}^{N}=A_{t}\left(K_{t}^{N}\right)^{\alpha^{N}}\left(H_{t}^{N}\right)^{1-\alpha^{N}} \\
& K_{D, t+1}=\left(1-\delta_{K}\right) K_{D, t}+I_{D, t}\left[1-\frac{\theta_{D}}{2}\left(\frac{I_{D, t}}{I_{D, t-1}}-1\right)^{2}\right] \\
& K_{N, t+1}=\left(1-\delta_{K}\right) K_{N, t}+I_{N, t}\left[1-\frac{\theta_{N}}{2}\left(\frac{I_{N, t}}{I_{N, t-1}}-1\right)^{2}\right] \\
& \omega H_{S, t}^{D}+(1-\omega) H_{B, t}^{D}=H_{t}^{D} \\
& \omega H_{S, t}^{N}+(1-\omega) H_{B, t}^{N}=H_{t}^{N} \\
& \omega C_{S, t}^{D}+(1-\omega) C_{B, t}^{D}=C_{t}^{D} \\
& \omega C_{S, t}^{N}+(1-\omega) C_{B, t}^{N}=C_{t}^{N} \\
& \omega D_{S, t}+(1-\omega) D_{B, t}=D_{t} \\
& \omega B_{S, t}+(1-\omega) B_{B, t}=0 \\
& K_{t}^{D}+K_{t}^{N}=K_{t} \\
& C_{t}^{D}+I_{t}^{D}+I_{t}^{N}+\frac{\phi^{D}}{2}\left(\Pi^{D}-1\right)^{2} Y_{t}^{D}=Y_{t}^{D} \\
& C_{t}^{N}+\frac{\phi^{N}}{2}\left(\Pi^{N}-1\right)^{2} Y_{t}^{N}=Y_{t}^{N} \\
& A_{t}=A_{t-1}^{\rho^{A}} \exp \left(e_{t}^{A}\right) \\
& \beta_{S}\left(i+i_{t}\right)=\left(\beta_{S}\left(i_{t-1}\right)\right)^{\rho^{M}}\left(\Pi_{t}^{\phi_{\Pi}}\right)^{1-\rho^{M}} \exp \left(e_{t}^{M}\right) \\
& \Pi_{t}^{D}=\frac{p_{t}^{D}}{p_{t-1}^{D}} \Pi_{t} \\
& \Pi_{t}^{N}=\frac{p_{t}^{N}}{p_{t-1}^{N}} \Pi_{t} \\
& 1=\left(p_{t}^{N}\right)^{\eta}\left(p_{t}^{D}\right)^{1-\eta}
\end{aligned}
$$




\section{Theoretical Basis for Lending Frictions}

The New Keynesian model outlined in Section 4 treated durable goods producers as exogenously subject to financing constraints. This section outlines several plausible theoretical mechanisms that would endogenously lead to such frictions. This section is based on two properties which are fundamentally features of durable goods: they take longer to build (the time effect) and face more volatile demand for their product due to its longevity (the volatility effect).

I use the workhorse model developed in in Tirole (2010) to analyze these features for several reasons. First, the model is simple, tractable, and allows for analytic results. Second, the model is flexible enough to easily incorporate stylized versions of the time and volatility effects. Finally, the solution to the model is an "investment multiplier" which says that the amount of funds that a firm is able to raise is a linear function of the value of its assets, which is the same functional form as the one found in the paper's more elaborate New Keynesian model. While not all of the parameters which determine the investment multiplier in this simplified context have direct counterparts in the larger model, this section provides some justification for my choice of working capital constraint and allows for some insightful comparative static exercises.

\section{D.1 The Simple Model}

There is a risk-neutral entrepreneur with sole access to the technology to produce their good. The production of the project is a function of the investment $X$ and effort $e \in\{l, h\}$ put into it. The entrepreneur has net worth $A$ that can be invested in the project; if he wishes to invest $X>A$, he must borrow $L=X-A$ from the banking sector, which is perfectly competitive and risk neutral.

The financing of the projects is non-trivial due to the presence of a moral hazard problem. If the entrepreneur exerts high effort $e_{h}$, the project succeeds with probability $p_{h}$ and produces according to the linear "production" function $R X$ where $R$ is the productivity or return of the project and $X \in[0, \infty)$. If the entrepreneur exerts low effort, the project succeeds with probabilty $p_{l}<p_{h}$ and the entrepreneur receives private benefits proportional to the level of investment $B X$. I assume that $p_{h} R>1>p_{l} R+B$, which tells us that the project is only NPV positive on a

per-unit basis in the case of high effort, and $p_{h} R<1+\frac{p_{h} B}{\Delta p}$, which leads to a bounded quantity of investment.

Because effort is not observable the contract cannot directly reward the entrepreneur for working hard, so it must be set up in an incentive-compatible manner to prevent them from running away with the money. This means that the entrepreneur must have enough "skin in the 
game" such that their private benefit from working hard exceeds their gains from shirking. The contracting problem will have individual rationality (IR) constraints for both the borrower and lender and an incentive compatibility (IC) constraint for the borrower.

Formally, their problem will be to split the investment $X$ and total expected successful return $R$ into separate pieces for both the lenders and borrowers. Incentive compatibility will require that the expected gain for the producer exceeds the private benefit of shirking:

$$
R_{b}\left(e_{h}\right) X \geq R_{b}\left(e_{l}\right) X \quad \Longrightarrow \quad p_{h} R_{b} X \geq p_{l} R_{b} X+B X \quad \Longrightarrow \quad R_{b} X \geq \frac{B X}{\Delta p}
$$

Here I've defined $\Delta p \equiv\left(p_{h}-p_{l}\right)$ to be the improvement in success probability that results from hard work. Because the per-unit net return of the project $\left(p_{h} R-1\right)$ is greater than 1 , the constrained investors will always have incentives to invest more in the project and they will only be limited by the set of contracts agreeable to the bank. Thus, their IC constraint will bind $\left(R_{b} X=\frac{B X}{\Delta p}\right)$ and their IR constraint will be slack. The positive net return will result in constrained investors optimally pledging their full wealth $A$ to the project so that $L=X-A$.

I now write the IR constraint for the bank knowing that the optimal contract will induce high effort on the part of the firm and that shirking will not be observed in equilibrium. I also allow for an outside option of investing their funds to earn a risk-free gross interest rate of $(1+i)$ :

$$
(1+i) L \geq p_{h} R_{l} X \quad \Longrightarrow \quad(1+i)(X-A) \geq p_{h}\left[R X-R_{b} X\right]
$$

The second inequality holds because the lender's return can be written as the total return minus the portion promised to the borrower. Because the entrepreneurs have market power in this setup, the IR constraint will bind for the bank and they will receive expected net returns of zero in equilibrium. Thus, combining equations (1) and (2) we get the following condition:

$$
\begin{aligned}
& (i+i)(X-A)=p_{h}\left[R X-R_{b} X\right] \Longrightarrow(1+i)(X-A)=p_{h}\left[R X-\frac{B X}{\Delta p}\right] \\
& \Longrightarrow X\left[1-\frac{p_{h}}{1+i}\left(R-\frac{B}{\Delta p}\right)\right]=A \Longrightarrow X=\left(\frac{1}{1-\frac{p_{h}}{1+i}\left[R-\frac{B}{\Delta p}\right]}\right) A
\end{aligned}
$$

Re-write the utility function as a linear function of $X$ and then plug in the investment multiplier derived above to write the borrower's net utility as follows: 


$$
U^{B}=\left(p_{h} R-1\right) X=\left(\frac{p_{h} R-1}{1-\frac{p_{h}}{1+i}\left[R-\frac{B}{\Delta p}\right]}\right) A
$$

Because all firms have constant returns to scale and the project has positive NPV, they will always want to invest as much as possible. The model solution will be an "investment multiplier" $k$ that reflects the return of the project, the outside interest rate, the project's probaiblity of success, and the severity of the moral hazard problem. In this setup, because $R$ is known by both parties before the investment is sunk, the contract can be interpreted as either debt or equity.

\section{D.2 The Time Effect}

In this section, the benefit of shirking $B$ is a random variable that is realized after financing is obtained but before effort is exerted. The disadvantage of having a production process that takes longer is that there will be some probability that the borrower receives a high enough outside option to deter them from working in later periods, and this will be taken into account by lenders.

There are two kinds of producers, durable and nondurable. Both types of producers share the same values of $p_{l}, p_{h}$, and $R$. In adddition, $B$ is observable and realized for nondurable producers prior to contracting so that they have the same solution as in the simple model.

Durable producers, however, draw their effort cost $\tilde{B}$ from a distrubtion with $\operatorname{CDF} F(\tilde{B})$ and support $\left[B_{l}, B_{h}\right]$. Crucially, $\tilde{B}$ is not realized until after financing is obtained and it cannot be contracted upon directly. For high effort to be exerted, the financing scheme must be incentive compatible. The contract will include a cutoff rule such that the borrower will exert effort if $\tilde{B} \leq B^{*}$. The borrower will exert effort as long as $R_{b} \geq \frac{B^{*}}{\Delta p}$. The lender's IR constraint will then be very similar to the previous section, with additional terms showing that the expected return will be lower to take account of the fact that the borrower can choose not to exert effort for high realizations of $\tilde{B}$.

$$
\begin{gathered}
(1+i) L \geq p_{h} R_{l} X F\left(B^{*}\right)+p_{l} R_{l} X\left(1-F\left(B^{*}\right)\right) \\
\Longrightarrow(1+i)(X-A) \geq\left(R-\frac{B^{*}}{\Delta p}\right) X\left[p_{h} F\left(B^{*}\right)+p_{l}\left(1-F\left(B^{*}\right)\right)\right] \equiv\left(R-\frac{B^{*}}{\Delta p}\right) \hat{p} X \\
\Longrightarrow X=\left(\frac{1}{1-\frac{\hat{p}}{1+i}\left[R-\frac{B^{*}}{\Delta p}\right]}\right) A \equiv M\left(B^{*}\right) A
\end{gathered}
$$


The borrower's net utility will then be the total per-unit net surplus of the project (the profitability, denoted $P\left(B^{*}\right)$ ) times the total amount invested (the scope, $M\left(B^{*}\right)$ ).

$U^{B}=\left[F\left(B^{*}\right)\left(p_{h} R-1\right)+\left(1-F\left(B^{*}\right)\right)\left(\left(p_{l} R-1\right)+\int_{B^{*}}^{B_{h}} \tilde{B} f(\tilde{B}) d \tilde{B}-1\right)\right] X \equiv P\left(B^{*}\right) M\left(B^{*}\right) A$

If $F\left(B^{*}\right)=1, \hat{p}=p_{h}, P\left(B^{*}\right)=\left(p_{h} R-1\right)$, and this collapses to the previous case. Because the borrower has market power, he will be free to set any cutoff that he likes. Choosing a value of $B^{*}$ will pin down the agreed upon return to the borrower $\frac{B^{*}}{\Delta p}$ while the lender will receive $R_{l}=R-\frac{B^{*}}{\Delta p}$. The borrower's choice of $B^{*}$ affects both the per-unit profitability of the project $P$ and its size $M$. In general, the value which maximizes his utility will depend on the parameterization and functional form assumptions, but it will be higher than $E[\tilde{B}]$. In effect, the borrower will optimally choose to offset the volatility friction by reducing the scope of the project (and hence ensuring incentive compatibility) by choosing a higher effort cost. Thus even in the case of risk-neutrality on the part of both the borrower and the lender, the information friction leads to a "risk-premium" faced by the durable borrower; their project will have a smaller scope, be less profitable, and exhibit more volatile profits than a nondurable producer who faces a known effort cost at the time of contracting.

\section{D.3 The Volatility Effect}

A simple way to extend the model to allow for durable goods to have more volatile demand is to treat the parameter $R$ as a random variable that is realized after financing is obtained but prior to effort being exerted. In this setup the per-unit returns to investment can be thought of as the price of the good being sold; in this context, durable producers face more volatile returns because their good has more a more volatile price. In this section I show that under a few additional assumptions the investment multiplier will decrease in the case of a mean-preserving spread in the return.

One issue that arises with this setup is that the optimal contract becomes more complicated. ${ }^{12}$ For simplicity, I will focus on fixed debt contracts in which income is not verifiable. If the firm makes the repayment agreed upon at the time of the contract, it keeps any remaining profit. If the firm does NOT make the payment, the bank is allowed to seize all proceeds from the project. As in the simple model the borrower is protected by limited liability and that the private benefits

\footnotetext{
${ }^{12}$ See Innes (1990) and Chiesa (1992), for example.
} 
to shirking $B X$ cannot be seized. ${ }^{13}$

$\tilde{R}$ has $\operatorname{CDF} F(\tilde{R})$ with support $\left[R_{l}, R_{h}\right]$ and is realized after investment has been sunk but before effort is exerted. In expectation, the investment is NPV positive only in the case of high effort: $p_{h} E[\tilde{R}]>1>p_{l} E[\tilde{R}]+B$. Because the money is sunk before $\tilde{R}$ is realized, however, there will be some realizations for which the project turns out to be NPV negative and thus would not have been financed if $\tilde{R}$ were observable by all parties prior to the investment being sunk. This hurts the borrower in several ways. Not only do low values of $\tilde{R}$ make the project less efficient, but they also exacerbate the incentive problem.

First consider the returns to the borrower. Define $R^{*}$ to be the return high enough to induce effort from the borrower (this will be determined later). Given a predetermined amount of financing $X$ and debt to the lender $B_{l}$, the borrower's utility will be a function of the realization of $\tilde{R}$. It must be the case that $R^{*} \geq \frac{B_{l}}{X}$; this means that the borrower would not choose to exert effort if it were not going to receive any of the benefit from working.

$$
U^{B}\left(\tilde{R} ; X, B_{l}\right)= \begin{cases}B X & p_{l} \tilde{R} X-B_{l}<0 \\ \left(p_{l} \tilde{R}+B\right) X-p_{l} B_{l} & \frac{B_{l}}{X} \leq \tilde{R} \leq R^{*} \\ p_{h} \tilde{R} X-p_{h} B_{l} & \tilde{R}>R^{*}\end{cases}
$$

The first case comes from the combination of limited liability on the part of the borrower and the realization of the private benefit regardless of the project's outcome. The second case corresponds to the region in which the return of the project exceeds the amount of debt owed, but is not high enough to induce high effort on the part of the borrower. The third case corresponds to the realizations of $\tilde{R}$ that are high enough to induce high effort.

The lender's return can be written similarly:

$$
U^{L}\left(\tilde{R} ; X, B_{l}\right)= \begin{cases}p_{l} \tilde{R} X & p_{h} \tilde{R} X-B_{l}<0 \\ p_{l} B_{l} & \frac{B_{l}}{X} \leq \tilde{R} \leq R^{*} \\ p_{h} B_{l} & \tilde{R}>R^{*}\end{cases}
$$

In the first case, the returns are inadequate to cover the debt payment, so the lender simply "grabs the entire cash register" and hence all of the proceeds from the project. In the second case, the returns are high enough to cover repayment, but they occur with a low probability because

\footnotetext{
${ }^{13}$ This corresponds to the "cash-register" model in Tirole (2010).
} 
the borrower is not exerting effort. In the third case, the returns are high enough to encourage behavior on the part of the borrower and the lender receives its payment with higher probability. These cases are illustrated in Figure 22.
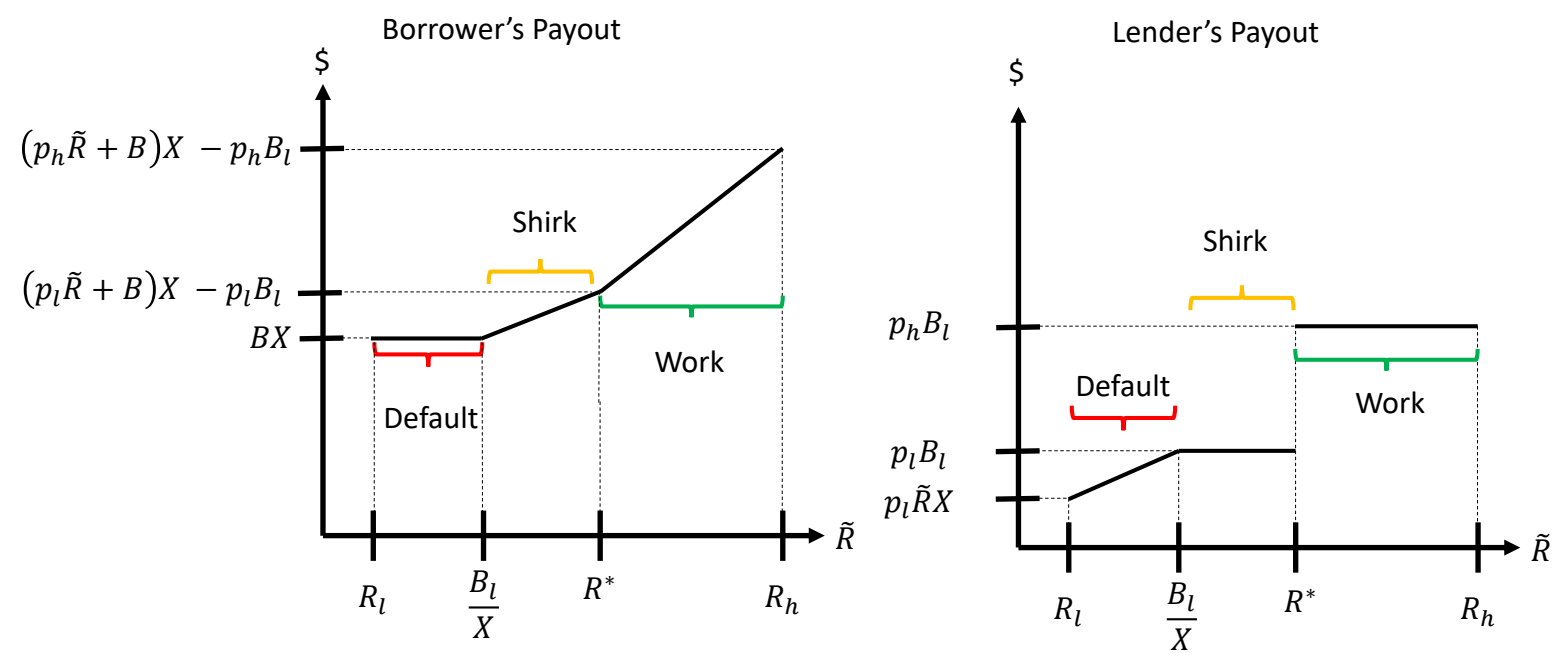

Figure 22: Borrower and Lender Payouts with Uncertain Project Return

Note: This figure shows the expected payouts to the borrower (left) and lender (right) as a function of the realized rate of return on the project $\tilde{R}$.

Incentive compatibility says that the borrower will exert effort as long as $p_{h}\left[\tilde{R} X-B_{l}\right] \geq$ $p_{l}\left[\tilde{R} X-B_{l}\right]+B X \Longrightarrow \tilde{R} \geq \frac{B}{\Delta p}+\frac{B_{l}}{X}$. Define $F(R)$ to be the CDF for the return, and define the following substitutions:

$$
\begin{gathered}
\alpha \equiv F\left(\frac{B_{l}}{X}\right)=F\left(R^{*}-\frac{B}{\Delta p}\right) \\
\beta \equiv F\left(R^{*}\right)-F\left(\frac{B_{l}}{X}\right)=F\left(R^{*}\right)-\alpha \\
\gamma \equiv 1-F\left(R^{*}\right)=1-\beta-\alpha
\end{gathered}
$$

These three terms correspond to the probabilities of $\tilde{R}$ falling in the default $(\alpha)$, shirk $(\beta)$, and work $(\gamma)$ regions of the support. After substituting this term for the lender's return, the borrower's expected utility at the time of contracting contracting will be: 


$$
E U^{B}(\tilde{R} ; X)=\alpha B X+\beta\left[B X+p_{l}\left(\hat{R} X-B_{l}\right)\right]+\gamma\left[p_{h}\left(\bar{R} X-B_{l}\right)\right]
$$

Where $\bar{R} \equiv E\left[\tilde{R} \mid \tilde{R} \geq R^{*}\right]$ and $\hat{R} \equiv E\left[\tilde{R} \mid \frac{B_{l}}{X} \leq \tilde{R}<R^{*}\right]$. Next I can write the returns for the lender as:

$$
E U^{L}(\tilde{R} ; X)=\alpha\left[p_{l} \underline{R} X\right]+\beta\left[p_{l} B_{l}\right]+\gamma\left[p_{h} B_{l}\right]
$$

Where $\underline{R} \equiv E\left[\tilde{R} \mid \tilde{R}<\frac{B_{l}}{X}\right]$. Now write out the modified IR and IC constraints:

$$
\begin{array}{ll}
(I R) & (1+i)(X-A) \geq \alpha\left[p_{l} \underline{R} X\right]+\beta\left[p_{l} B_{l}\right]+\gamma\left[p_{h} B_{l}\right] \\
(I C) \quad & B_{l} \leq\left(R^{*}-\frac{B}{\Delta p}\right) X
\end{array}
$$

Here it is crucial to remember that while $\tilde{R}$ is a random variable, the payout to the lender $B_{l}$ must be decided ahead of time, and so the IC constraint will bind with equality at $R^{*}$. This implies that $B_{l}=\left(R^{*}-\frac{B}{\Delta p}\right) X$. Because firms are perfectly competitive, the solution will be the point at which the IR constraint holds with equality:

$$
\begin{gathered}
(1+i)(X-A)=\alpha\left[p_{l} \underline{R} X\right]+B_{l}\left[\beta p_{l}+\gamma p_{h}\right] \\
\Longrightarrow(1+i) X-(1+i) A=X\left[\alpha p_{l} \underline{R}+\left(\beta p_{l}+\gamma p_{h}\right)\left(R^{*}-\frac{B}{\Delta p}\right)\right] \\
\Longrightarrow X=\left(\frac{1}{1-\frac{1}{1+i}\left[\alpha p_{l} \underline{R}+\left(\beta p_{l}+\gamma p_{h}\right)\left(R^{*}-\frac{B}{\Delta p}\right)\right]}\right) A
\end{gathered}
$$

Define the lender's per-unit expected return as $Q \equiv \alpha p_{l} \underline{R}+\left(\beta p_{l}+\gamma p_{h}\right)\left(R^{*}-\frac{B}{\Delta p}\right)$. The model behavior will depend crucially on the partial derivative of the investment multiplier with respect to $R^{*}$. Substituting $\frac{B_{l}}{X}=R^{*}-\frac{B}{\Delta p}$ and writing out the conditional expectation yields: 


$$
F\left(R^{*}-\frac{B}{\Delta p}\right) \frac{1}{F\left(R^{*}-\frac{B}{\Delta p}\right)} \int_{R_{l}}^{R^{*}-\frac{B}{\Delta p}} \tilde{R} f(\tilde{R}) d \tilde{R}=\int_{R_{l}}^{R^{*}-\frac{B}{\Delta p}} \tilde{R} f(\tilde{R}) d \tilde{R}
$$

The fundamental theorem of calculus says that the derivative of this integral with respect to $R^{*}$ will be $\left(R^{*}-\frac{B}{\Delta p}\right) f\left(R^{*}-\frac{B}{\Delta p}\right)$, which will always be positive, so the integral will be strictly increasing in $R^{*}$. A higher value of $R^{*}$ will make default more likely and, when it occurs, more profitable for the lender (because there will be higher values of $\tilde{R}$ which result in default). While this is independent of the distribution $F(\tilde{R})$, the effects will be more complicated for the second term in $Q$. While $\gamma$ is decreasing in $R^{*}$, the effect on $\beta$ will depend on the distribution $F(\tilde{R})$.

Now, the only thing left is to determine the optimal choice of $R^{*}$. To find this value, first re-write the borrower's utility function to show that it is linear in $X$ :

$$
\begin{aligned}
& E U^{B}=\alpha B X+\beta\left[B X+p_{l}\left(\hat{R} X-B_{l}\right)\right]+\gamma\left[p_{h}\left(\bar{R} X-B_{l}\right)\right] \Longrightarrow \\
& E U^{B}=X\left[(\alpha+\beta) B+\beta p_{l} \hat{R}+\gamma p_{h} \bar{R}-\left(\beta p_{l}+\gamma p_{h}\right)\left(R^{*}-\frac{B}{\Delta p}\right)\right]
\end{aligned}
$$

Combining this equation with the the previous one yields the following form for the borrower's utility entirely as a function of the cutoff return $R^{*}$ :

$$
E U^{B}=\left(\frac{(\alpha+\beta) B+\beta p_{l} \hat{R}+\gamma p_{h} \bar{R}-\left(\beta p_{l}+\gamma p_{h}\right)\left(R^{*}-\frac{B}{\Delta p}\right)}{1-\frac{1}{1+i}\left[\alpha p_{l} \underline{R}+\left(\beta p_{l}+\gamma p_{h}\right)\left(R^{*}-\frac{B}{\Delta p}\right)\right]}\right) A
$$

Note when $R$ is fixed and effort is always exerted in equilibrium, this collapses to Equation 75 . While there is a continuum of implementable contracts, because the borrower has market power it will choose $R^{*}$ (which will subsequently pin down the amount borrowed and the lender's return) that maximizes its utility. While this expression does not necessarily have a closed-form solution, simulations suggest the utility and the investment multiplier at the optimum are decreasing in the volatility of $\tilde{R}$ for reasonable choices of distributions and parameters. This suggests that firms with more volatile returns face higher barriers to obtaining financing due to the frictions caused by moral hazard. 